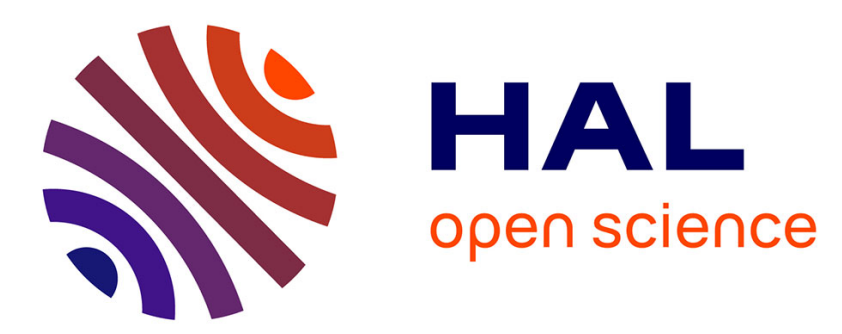

\title{
Analyzing the Dynamic Impact of Electricity Futures on Revenue and Risk of Renewable Energy in China
}

\author{
Yue Zhang, Arash Farnoosh
}

\section{To cite this version:}

Yue Zhang, Arash Farnoosh. Analyzing the Dynamic Impact of Electricity Futures on Revenue and Risk of Renewable Energy in China. Energy Policy, 2019, 132, pp.678-690. 10.1016/j.enpol.2019.06.011 . hal-02264847

\section{HAL Id: hal-02264847 \\ https://hal-ifp.archives-ouvertes.fr/hal-02264847}

Submitted on 7 Aug 2019

HAL is a multi-disciplinary open access archive for the deposit and dissemination of scientific research documents, whether they are published or not. The documents may come from teaching and research institutions in France or abroad, or from public or private research centers.
L'archive ouverte pluridisciplinaire HAL, est destinée au dépôt et à la diffusion de documents scientifiques de niveau recherche, publiés ou non, émanant des établissements d'enseignement et de recherche français ou étrangers, des laboratoires publics ou privés. 


\title{
Analyzing the Dynamic Impact of Electricity Futures on Revenue and Risk of Renewable Energy in China
}

\author{
Yue Zhang ${ }^{\mathrm{a}, *}$, Arash Farnoosh ${ }^{\mathrm{b}}$ \\ aAcademy of Chinese Energy Strategy, China University of Petroleum-Beijing, Changping, Beijing 102249, China \\ ${ }^{\mathrm{b}}$ IFP Energies Nouvelles, IFP School, 228-232 Avenue Napoleon Bonaparte, F-92852 Rueil-Malmaison, France
}

\begin{abstract}
Though the electricity market in China has gone through several reforms in the last few decades, the market is still not completely liberalized. The wholesale prices are regulated and for renewable it is based on feed-in tariff; there is not yet a competitive spot or derivative market concerning the generation side. Furthermore, with great potential, renewable energy is being gradually promoted by the government to compete freely with conventional energies. However, it is hard for a renewable generator to survive without subsidy. So, in this paper we propose a new round of revolution in power sector to introduce electricity futures into China with the expectation of perfecting the market and providing a proper hedging tool for renewable plants. We make an estimation of the risk premium and then simulate the futures prices in China's market. To support the establishment of the futures contracts, we also propose two pricing mechanisms: Demand-side price \& Opportunity cost price and study their effects on the futures. Finally, some suggestions with regard to the construction of futures market in China and the operational strategy for renewable plants are given.
\end{abstract}

Key Words: Electricity Market, Spot Prices, Futures Prices, Hedging Strategy, E-mail: zhangyueno.8@163.com (Yue Zhang); arash.farnoosh@ifpen.fr (Arash Farnoosh).

Declarations of interest: none. 
Renewable Energy

\section{Introduction}

As the basic industry of a country, electricity is related to the people's livelihood, so its importance is self-evident. However, it is a special commodity. Besides, due to the difficulty of storage and instantaneous matching of demand and supply electricity has been a natural monopoly for a long time. Many developed countries began to carry out the liberalization of the electricity market since 1980s aiming to break the monopoly, introduce competition into the market and optimize the energy mix. For instance, north Europe established the first transnational electricity market in 1995 Nord Pool. This market has a sound mechanism and huge trading volume of both spot and forward contracts. As one of the fastest growing developing countries, China's electricity consumption has grown rapidly. According to BP statistics, China's electricity consumption in 2016 leapt to the first in the world, accounting for $24.8 \%$ of the total consumption. Besides, demand of electricity has a very low elasticity: in 2015 China's primary energy consumption elasticity is 0.13 , while that of power is only 0.07 (National Bureau of Statistics).

In order to go towards liberalization, electricity market in China has gone through several reforms: since 1997 the government had been gradually separated from power enterprises, which greatly stimulated the power plants; in 1998, the State Power Corporation put forward the framework of "separating power plants and power grids and establishing generation side market"; at the beginning of 2002, the implementation of <Power System Reform Program> broke the monopoly in E-mail: zhangyueno.8@163.com (Yue Zhang); arash.farnoosh@ifpen.fr (Arash Farnoosh). 
generation side. Nevertheless, the electricity market in China is still underdeveloped, and there is still no perfectly competitive generation market as Nord Pool. The wholesale power prices nowadays in the market are regulated and are still based on feed-in tariff. There are benchmarks for electricity wholesale prices which are formulated by the government according to the different average costs in different provinces or areas. And National Development and Reform Commission (NDRC) is responsible for the revision of the benchmarks every year. Furthermore, the energy mix in China is not environmentally friendly: the installed capacity of thermal power accounts for $65.93 \%$. As a result, air pollution has become one of the most severe problems and according to BP statistics the emissions of carbon dioxide reached 9.123 billion tons in 2016, accounting for $27.3 \%$ of the world's total emissions and making China the largest $\mathrm{CO} 2$ emitter in the world.

These situations of China's electricity market urgently need a new round of revolution. One promising and practical solution could be renewable energy which is critical for the power market to substitute the high-percentage thermal power and alleviate the severe environmental problems. But it is hard for the renewable power generators to survive without the government's support in China due to the relatively high costs and the unstable supply. According to the <Renewable Energy Law>, electricity generated by renewable power plants shall be fully purchased by the grid at fixed feed-in tariff. And the price is much higher (nearly double) than thermal power which aims to guarantee the revenue of renewable plants. However, the government is actively reducing the subsidy on the renewables and promoting a competitive E-mail: zhangyueno.8@163.com (Yue Zhang); arash.farnoosh@ifpen.fr (Arash Farnoosh). 
wholesale price. National Energy Administration plans to make wind power freely compete with thermal by 2020 .

However, a competitive market needs a new and suitable pricing mechanism to match the power demand and supply without harming the benefits of both aspects. Therefore, we propose two pricing mechanisms in this paper. One is Demand-side Price. It uses power demand that is predicted by the Back Propagation Neural Network Model (BPNN) as the most important input. The other is Opportunity Cost Price which is based on the trade price of carbon dioxide emission.

Furthermore, the experience in developed power market shows that the wholesale price will be super volatile due to the noneconomical storage, instantaneous matching requirements and low demand elasticity. And the volatility will damage the renewable plants even more. So, there is a need to establish a sound financial market for the renewable power plants to hedge the price risk in wholesale market and to discover the real price level in the market. The appropriate usage of electricity futures will help the renewable power plants to guarantee the profits in a market with perfect competition and even drive out the thermal power plants without the help of government.

So, expecting to stimulate the healthy development of renewable generators in a competitive wholesale market, this paper introduces wholesale pricing mechanisms and electricity futures into Chinese market. And thereafter finds out the impact on profits and risk levels of renewable power plants in the proposed market.

The remainder of the paper is organized as follows: Section 2 summarizes the E-mail: zhangyueno.8@163.com (Yue Zhang); arash.farnoosh@ifpen.fr (Arash Farnoosh). 
relevant literature of electricity futures which includes the characteristics, relationship with spot market and its functions, and then points out that the existing literature has not taken too much effort on the impact of spot pricing mechanism on futures prices or quantitative research on China's electricity market. In Section 3, we introduce the main pricing models and other methodologies used in this paper. Section 4 establishes electricity futures market in China according to the literature on Nord Pool. Based on different pricing mechanisms, a case study of Taiwan province is given is Section 5 that simulates the prices of futures contracts and analyzes the operational strategies, benefits and risk level of a renewable power plant. Section 6 summarizes the results of the above sections, and puts forward some constructive suggestions.

\section{Literature Review}

\subsection{The Introduction and Characteristics of Electricity Futures}

The concept of electricity futures was firstly put forward by Scwheppe et al. (1997). They applied the definition of normal commodity futures on the electricity. And a few countries were intending to make liberalization and deregulation in their electricity sector at that time. The brand new competitive power market, together with the special physical attributes of electricity have brought new challenges never seen neither in spot nor in financial markets (Fanelli et al., 2016). Therefore, electricity futures rapidly aroused widespread concern in those countries. To stabilize the electricity market and increase the efficiency of the power system, they developed their own power derivatives market. Plenty of researches focus on those large and E-mail: zhangyueno.8@163.com (Yue Zhang); arash.farnoosh@ifpen.fr (Arash Farnoosh). 
mature markets, such as Pennsylvania-New Jersey-Maryland (PJM) market in US, London International Petroleum Exchange (IPE) in UK, the Nord Pool in Nordic countries and EEX in Germany (Geman et al., n.d.; Longstaff and Wang, 2004; Karakatsani and Bunn, 2005; Kolos and Ronn, 2008). Among all of the developed market, Nord Pool has the highest value to take as a reference to establish electricity futures in China's electricity market due to its sound market mechanism, large amount of transactions, and perfect market liquidity (He,Chuan, 2010).

Electricity futures satisfy most of the qualities of commodity futures: high price volatility, huge trading volume, large number of market participants, and highly standardized underlying asset (Liu,Feng, 2005). However, electricity also has some special properties compared with other commodities. First, electricity is characterized by limited storability, which makes the supply inelastic to the price changes (Fanelli et al., 2016; Bessembinder and Lemmon, 2002). Besides, it also results in some differences in the physical delivery. Different from other contracts, its delivery remains in a specific time span with a fixed amount in each hour (Benth and Koekebakker, 2008). Second, due to the existence of peak and valley in electricity demand, the electricity futures contracts are usually designed in two parts: peak contracts and valley contracts (Zhang, Shao Hua, 2001).

\subsection{Research on the Electricity Futures Price}

Due to the unique characteristics of uneconomic storage and synchronous demand and supply, the correlation between spot and futures prices of electricity is not that close as other commodities (Moulton, 2005). Nevertheless, the well mastered E-mail: zhangyueno.8@163.com (Yue Zhang); arash.farnoosh@ifpen.fr (Arash Farnoosh). 
of spot prices, futures prices and their relationships are essential for energy traders and power plants to use them as an effective tool. Therefore, tones of literature focus on that and try to grasp precisely of both spot and futures prices in power sector. Fama and French (1987) summarized two theories of futures prices: one is storage theory which argues the price of a forward contract is composed of spot price of the commodity, financial costs, warehousing costs and convenience yield; the other theory is expectation theory, which points out the forward price equals the expected spot price plus a risk premium and the premium is used to compensate the uncertainty of the price in future. The second theory is the main starting point of electricity futures pricing model because of the no direct storability of power (Huisman and Kilic, 2012). Huisman and Kilic also divide electricity into perfectly (such as fossil fuel) and imperfectly (such as wind, solar) storable energy according to the works of Douglas and Popova (2008) and Treslong and Huisman (2009). Their research shows that power futures price model with perfect storability should depend on price expectation while model with imperfect storability needs to include risk premium. Being aware of the importance of risk premium to the prices of power futures, scholars establish different empirical models to study it using data from different mature power markets. Botterud et al. (2002) find positive risk premium with high fluctuation from futures contracts in Nord Pool market. Kolos and Ronn (2008) and Lucia and Torró (2008) get the same results in German EEX market and Nord Pool with different contract maturities. However, Longstaff and Wang (2004) and Karakatsani and Bunn (2005) find the futures price exceeds the spot price in PJM and E-mail: zhangyueno.8@163.com (Yue Zhang); arash.farnoosh@ifpen.fr (Arash Farnoosh). Declarations of interest: none. 
UK market which indicate a negative risk premium and a backwardation. Besides, a lot of conducted studies also shed light on the factors that influence risk premium. Lucia and Torró (2011) prove that the risk premium is time-varying and relates to the variance and skewness of spot prices. Botterud et al. (2010) analyze 11-year data in a hydro-dominated market and find the risk premium is strongly related to reservoir level, inflow and power demand.

\subsection{Research on the Function of Electricity Futures}

Just as other commodity futures, price discovery, risk adverse and hedging are three main functions of electricity futures contracts. And hedging plays the most important role among them. It substitutes the underlying price risk with a new type of risk - basis risk (difference between the price of forward contracts and underlying assets) (Edwards and Canter, 1995). However, the special attributes of power that we mentioned make the tradeoff between the two different kinds of risks more challenging (Frestad, 2012). Lui (2001) reputes that the difficulty of delivery and lack of correlation between futures and spot prices lead to a loss of hedging ability of futures contracts. Since the delivery problem is harder to solve, lots of scholars focus on the crucial issue to find an optimal hedging ratio to offset the greater basis risk and hence, to improve the hedging performance. Two methods are widely used to determine the time-varying hedge ratios: the first one is Generalized Autoregressive Conditional Heteroscedasticity model $(\mathrm{GARCH})$ which estimates the conditional second order trends of the spot and futures return (Billio et al., 2017; Giovanna Zanotti et al., 2010; Kroner and Sultan, 1993; Lai et al., 2017); the second approach E-mail: zhangyueno.8@163.com (Yue Zhang); arash.farnoosh@ifpen.fr (Arash Farnoosh). 
uses OLS regression to make an estimation of the time-varying hedge ratios (Lee et al., 2010; Moulton, 2005). Lien et al. (2002) study different models in different futures markets and find out GARCH model does not outperform the OLS hedging strategy. Concerning hedging strategies, Miller, T and Thompson, A (2002) point out a better hedging results in the last few days of maturity using data in NYMEX market.

In summary, the unique attributes of electricity as an underlying asset leads to the fact that electricity futures have both the excellent characteristics of traditional commodity futures and the unique challenges. And the rational use of electricity futures in a sound and mature power market can reduce market risk for market participants and even become a good speculative tool. In addition, the expectation theory and hedging models are quite mature to explain the futures prices and find an optimal hedging ratio to improve the effectiveness of the contract. Furthermore, international experience shows that suitable financial mechanisms and tools will ensure an effective and efficient renewable energy system (Bazilian et al., 2014; Roques, 2008).

Based on the literature, the contributions of the paper lie in three aspects. First of all, few relevant literature conduct a reasonable quantitative analysis on China's electricity futures market and its functions. Therefore, this paper introduces electricity futures into power market of China and a quantitative research about the price of futures contracts and the impact on power plants are processed. Second, barely no research focuses on the impacts of pricing mechanisms in wholesale market on the price of futures contract and its functions. Thus, the futures prices under the different E-mail: zhangyueno.8@163.com (Yue Zhang); arash.farnoosh@ifpen.fr (Arash Farnoosh). 
pricing mechanisms are simulated in this paper and their characteristics are compared and analyzed. Finally, we also further analyze the strategies, benefits and risk level of China's renewable plants when using the electricity futures in different scenarios. And based on that, some relevant suggestions are put forward.

\section{Methodology and Model}

\subsection{Back Propagation Neural Network (BPNN)}

Neural Network (NN) algorithms are mainly based on statistical models and human biological neural networks (Grolinger et al., 2016). They can perform as human brain to process information and can be used to deal with complex relationships between inputs and outputs (Rahman et al., 2016). Back Propagation Neural Network (BPNN) is one of the most widely used algorithms and it belongs to the teacher-guided learning method. BPNN includes two processes: the forward propagating of information and the backward transmitted errors from the output layer to the input layer. A basic BPNN model has three layers: input, hidden and output layers. The three layers are connected by connection strengths called weights $\left(W_{i}\right)$ and the gradient drop algorithm is used to adjust the weights (Kazanasmaz et al., 2009). The transfer function adopted for neurons is a logistic function $\mathrm{f}\left(Z_{i}\right)$ which is showed in the following formulas. And the basic principle of BPNN can be found in Figure 1.

$$
\begin{gathered}
\mathrm{f}\left(Z_{i}\right)=\frac{1}{1+e^{-Z_{i}}} \\
Z_{i}=\sum_{j=1}^{n} w_{i j} \times x_{i}+\beta_{i}
\end{gathered}
$$


Where, $Z_{i}$ is the weighted sum of the inputs; $w_{i j}$ is the weight for neuron $\mathrm{j}$ to $\mathrm{i} ; x_{i}$ is the signal from $\mathrm{jth}$ neuron; $\beta_{i}$ is the basic of neuron $\mathrm{i}$.

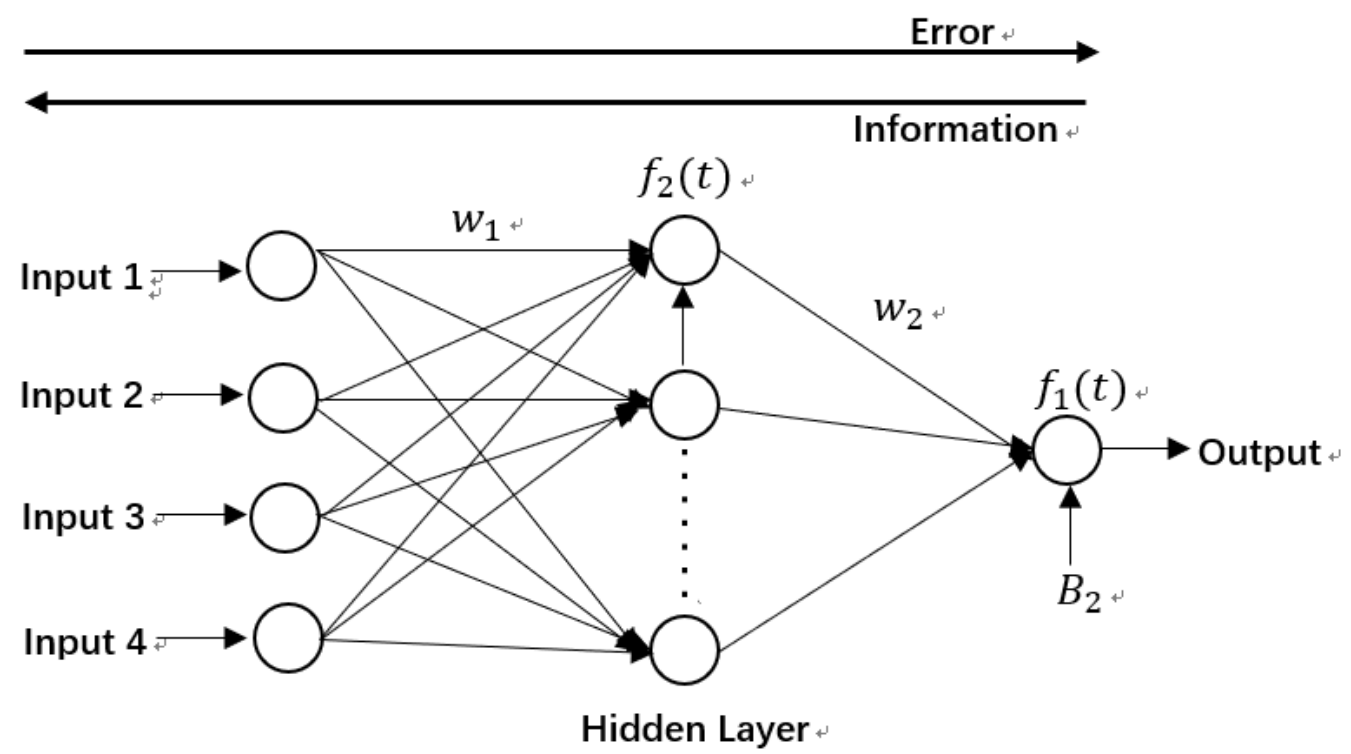

Figure 1: The Basic Principle of BPNN

A successfully trained BPNN system can be used to accurately predict the output. Compared with other forecasting methods, BPNN has 3 unique characteristics: One is accuracy. Kialashaki and Reisel (2013) proved that NN performs better than multiple linear regression in terms of coefficient of determination $\left(\mathrm{R}^{2}\right)$ when forecasting the energy demand of the residential sector in the United State. The second characteristic is simplified formation. BPNN is not restricted to formation of regression compared to econometrics forecast. Ardakani and Ardehali (2014) tried many different formations of regressions and found that in comparison with $\mathrm{NN}$ model, none of those regressions implement a sufficient accuracy for long-term electrical energy consumption. The final feature is fast speed. Chandra and Sharma (2015) proposed a method that can speed up the $\mathrm{NN}$ with little increase in the forecast error by parameterizing the weight matrix using low rank factorization and periodic functions. 
These three features make BPNN extremely suitable for estimation of the energy demand for a nation and even a specific building. Rahman et al. (2016) used BPNN to proposed an electricity generation forecasting system that could successfully predict the electricity consumption for the United State. Jain et al. (2014) gave a relatively accurate prediction of the power usage of a fully air-conditioned office building with 40 floors in Hong Kong using a NN model with nine inputs. Panapakidis (2016) developed day-ahead and hour-ahead load predictions based on $\mathrm{NN}$ and found out that clustering methodology makes the forecasting accuracies enhanced in both scenarios.

In this paper, a 3-layers BPNN model with inputs of historical demands, temperature, season and weekend is trained to predict the hourly electricity demands. The model is showed in Figure 2.

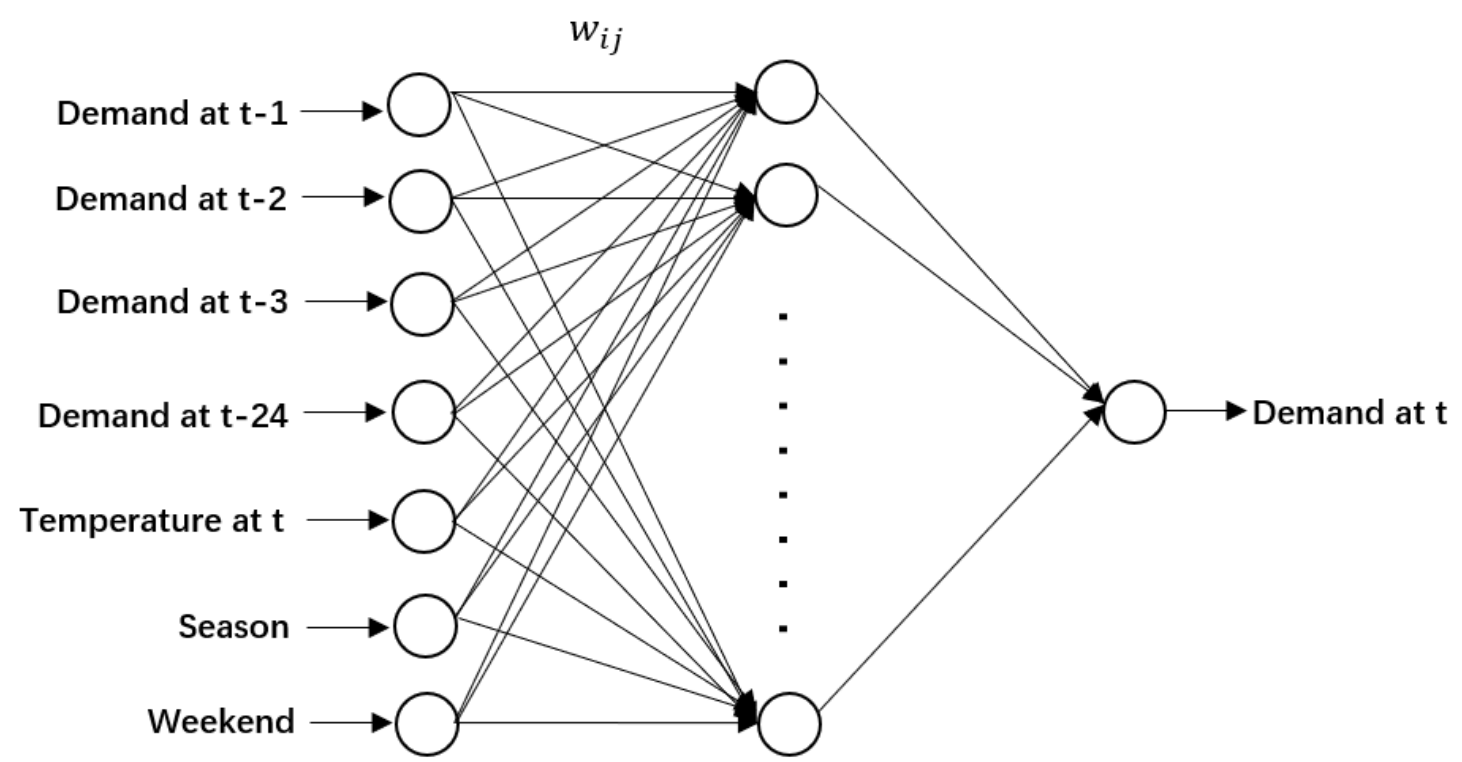

Figure 2: Topology of the 3-layers BPNN

\subsection{Pricing Mechanisms for Wholesale Market (Scenario Setting)}

Black (1986) studies the success and failure factors of futures contracts and she argues that they are easier to succeed when the underlying commodity prices have E-mail: zhangyueno.8@163.com (Yue Zhang); arash.farnoosh@ifpen.fr (Arash Farnoosh). 
high volatility and the traders will have more interests on them. So, in this paper, we propose two alternative pricing mechanisms for the wholesale power market of China to substitute the regulated prices and ensure the successful performance of electricity futures contracts.

\subsubsection{Pricing Mechanism I: Demand-side Pricing (DSP)}

We first adopt the demand-side pricing model proposed by Zhang,Cai Qing (2004) to form day-ahead wholesale electricity prices. The model is under the three hypotheses: demand is elastic; there are $\mathrm{m}$ generators and $\mathrm{n}$ customers in the market; the supply functions $\left(\mathrm{p}=\mathrm{f}\left(q_{s}\right)\right)$ and demand functions $\left(q_{d}=\mathrm{g}(\mathrm{p})\right)$ are known.

The formation process of demand-side wholesale prices is as following:

1. Power plants forecast daily demands $\left(q_{s}\right)$ according to the historical data;

2. Power plants offer a price (p) according to the forecasted demand;

3. Demand sides give a feedback demand $\left(q_{d}\right)$ according to the offered price $(\mathrm{p})$;

4. The generation plants decide whether to accept the demand or offer another price according to the difference between $q_{d}$ and $q_{s}$.

The mathematical form of the model can be described as follow:

Objective: The equilibrium condition under this model is that the difference between the load predicted by the power generation side and the feedback load by the demand side is within a small range. So, the objective function of the model based on the demand side electricity price can be described as:

$$
\operatorname{Min} \sum_{t=1}^{24}\left[\sum_{k=1}^{m} f_{k}^{-1}\left(p_{k t}\right)-\sum_{j=1}^{n} g_{j}\left(p_{t}\right)\right]^{2}
$$

Where $p_{t}=\frac{\sum_{k=1}^{m} p_{k t} \times f_{k}^{-1}\left(p_{k t}\right)}{\sum_{k=1}^{m} f_{k}^{-1}\left(p_{k t}\right)} ; p_{t}$ is the average offer price; $p_{k t}$ is the offer E-mail: zhangyueno.8@163.com (Yue Zhang); arash.farnoosh@ifpen.fr (Arash Farnoosh). 
price of generator $\mathrm{k}$ at $\mathrm{t} ; f_{k}^{-1}\left(p_{k t}\right)$ is the inverse supply function.

\section{Constraints:}

1.Capacity constraint: The power generation of each power plant on the power generation side shall not exceed the maximum power generation allowed by the system $\left(L_{k}\right)$. In addition, the total load on the demand side must not exceed the total load allowed by the whole system.

$$
\begin{gathered}
f_{k}^{-1}\left(p_{k t}\right) \leq L_{k} \\
\sum_{j=1}^{n} g_{j}\left(p_{t}\right) \leq \sum_{k=1}^{m} L_{k}
\end{gathered}
$$

Where $L_{k}$ is the maximum capacity of generator $\mathrm{k}$.

2.Price constraint: In order to ensure the fairness and stability of the wholesale market, the price needs to be under the government's ceiling price.

$$
p_{k t} \leq P
$$

Where $\mathrm{P}$ is the upper limit of feed-in tariff.

3.Supply constraint: The power plant will predict the power demand of the next trading period and make relevant preparations. So, the power supply on the supply side has a certain rigidity, and the actual supply quantity needs to be within a certain range $(\mu)$ of the forecast current demand.

$$
(1-\mu) \times q_{s} \leq \sum_{k=1}^{m} f_{k}^{-1}\left(p_{k t}\right) \leq(1+\mu) \times q_{s}
$$

Where $\mu$ is the changeable percentage of forecasted demand.

\subsubsection{Pricing Mechanism II: Opportunity Cost Pricing (OCP)}

According to Dufour and Cheng (2008), opportunity cost is the value of the E-mail: zhangyueno.8@163.com (Yue Zhang); arash.farnoosh@ifpen.fr (Arash Farnoosh). 
choice in terms of the best alternative while making a decision. So, when applied to power sector, the wholesale prices should be the price of conventional energy plus the external value.

Kallabis et al. (2015) analyze the Germany market using a parsimonious fundamental model and point out that the $\mathrm{CO} 2$ emission price has a strong impact on the futures market. By examining the futures prices of U.K and Germany, Huisman and Kiliç (2015) find that electricity prices should include market price of emission as it is a cost factor for power plants. Besides, they also point out that the emission price passed through to electricity price is time-varying. So, we apply the time-varying CO2 price as the most important external value of renewable electricity when compared to conventional.

So, according to the OCP model, the wholesale prices should be:

$$
p_{w}=p_{c}+c \times \gamma
$$

Where $p_{w}$ is the wholesale price of power; $p_{c}$ is the wholesale price of conventional energy; $\mathrm{c}$ is the price of carbon trading and $\gamma$ is a constant conversion parameter.

The two wholesale pricing mechanisms we proposed are both market-based. However, under DSP the will of the consumers is taken into account in the formulation of the price and therefore enable the demand side to participate in the formation of the wholesale price, and even lead the pricing. Besides, the demand-side pricing model reflects the clearing price of supply and demand in the power market. But OCP is an external price, and the volatility of the price only comes from the price 
of carbon trading which can be regarded as Pigovian tax.

\subsection{Expectation Theory}

In this part, we summarize the expectation theory of Fama and French (1987) as we will follow their method in this paper. In the expectation theory, a forward contract price equals to the sum of expected spot price and expected risk premium. And according to Hull (2001), the futures price in the expectation theory can be expressed as:

$$
F_{t, T}=E_{t}\left(S_{t+T}\right) e^{\left(r_{T}-i_{T}\right)}=E_{t}\left(S_{t+T}\right) e^{-R P_{t}}
$$

Where, $F_{t, T}$ is the price of electricity futures at time $t$ with holding period of $\mathrm{T}$; $E_{t}\left(S_{t+T}\right)$ is the expected spot price at $\mathrm{t}+\mathrm{T} ; r_{T}$ is the risk-free interest rate for the holding period $\mathrm{T} ; i_{T}$ is the discount rate for the underlying commodity; $R P_{t, T}$ is risk premium at $\mathrm{t}$ with holding period $\mathrm{T}$.

Botterud et al. (2010) explains the risk premium from the risk aversion level of dominant market participants in the market. A risk-averse producer of the commodity will short futures contracts in order to hedge his physical position. So, when the producer is dominant or most producer do the same in this derivative market, the market will result in excess of supply in terms of contracts. Futures price will be lower than expected spot price and the risk premium will be negative $\left(R P_{t, T}<0\right)$. A positive risk premium will occur when the demand side is more risk averse.

And if the hypothesis of an accurate price expectation exists, the risk premium could be expressed as follow:

$$
R P_{t, T}=\ln \left(S_{t+T}\right)-\ln \left(F_{t, T}\right)
$$

E-mail: zhangyueno.8@163.com (Yue Zhang); arash.farnoosh@ifpen.fr (Arash Farnoosh).

Declarations of interest: none. 


\subsection{Hedging Strategy}

In this paper, we use delta hedging strategy (Hull, 2001) due to its simplicity and relatively high effectiveness. The following regression should be made to get the optimal hedging ratio $\beta$.

$$
\Delta S_{t}=\alpha+\beta \times \Delta F_{t}+\varepsilon
$$

Where $\Delta S_{t}$ and $\Delta F_{t}$ are daily changes in spot and futures prices respectively.

And the optimal number of contracts a participant should long or short in the futures market should be:

$$
\text { Number of contracts }=\beta \times \frac{\text { value of spot position }}{\text { value of a futures contract }}
$$

The details of the process in this paper can be found in the flowchart in Figure 3. 


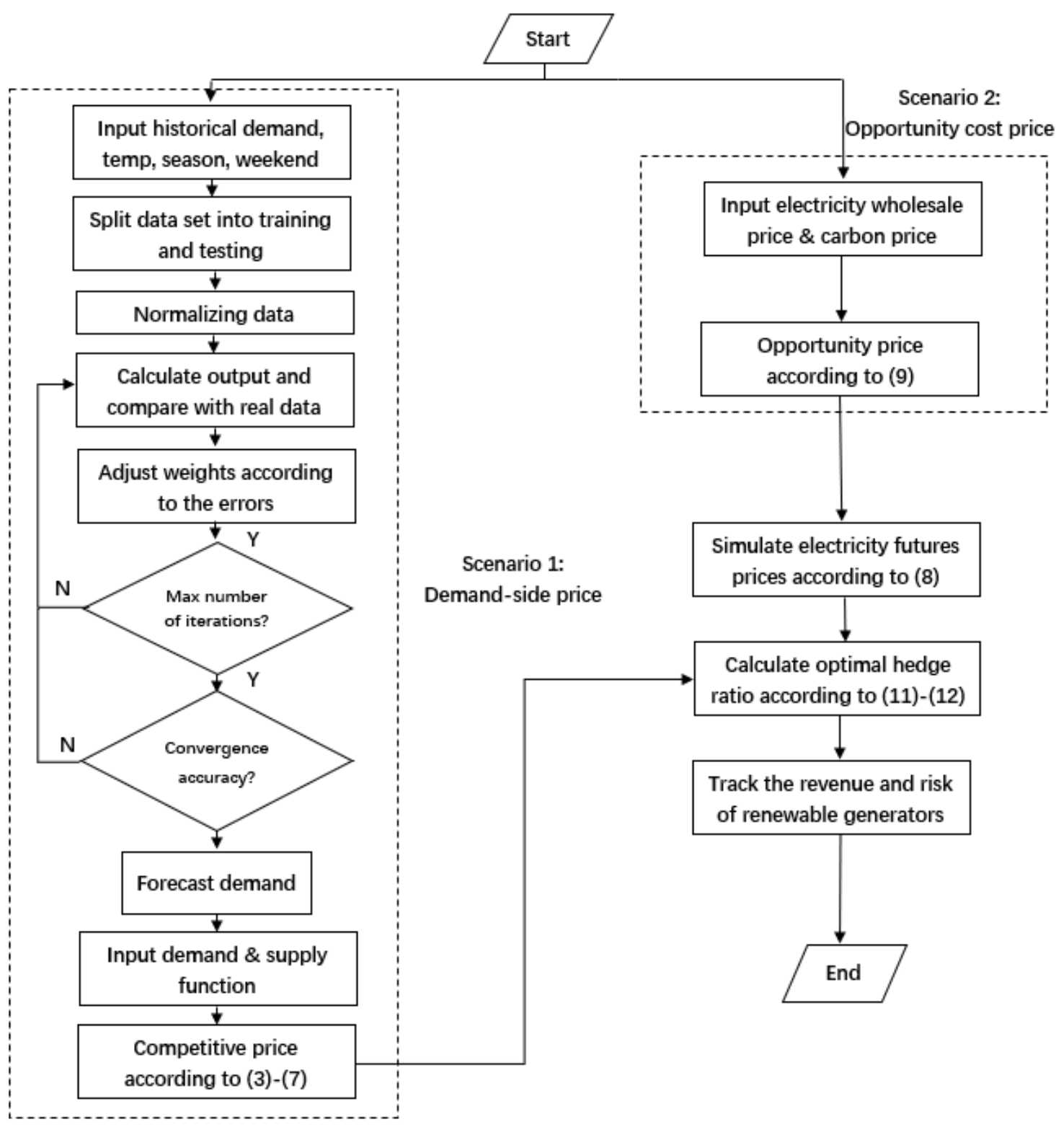

Figure 3: The Flowchart of Model

\section{Establish an Electricity Futures Market}

There is no electricity derivative market in China yet and it is unreasonable to directly use the data in any mature foreign derivative market due to the different costs and market structures. So, we will make a simulation of the daily electricity futures prices using the multi-factor econometric model proposed by Botterud et al. (2010).

They analyze the relationship of spot and futures prices from 1996-2006 in Nord Pool market based on expectation theory and find out that the risk premium is also E-mail: zhangyueno.8@163.com (Yue Zhang); arash.farnoosh@ifpen.fr (Arash Farnoosh).

Declarations of interest: none. 
related to the physical statements of the market, such as the water reservoirs and inflow of water. Besides, the results are further confirmed with even longer time span (13 years) by Weron and Zator (2014). So, we will use the regression model and results of Botterud to simulate the daily prices of supposed electricity futures in China. The reasons are listed as following: First, Botterud took Nord Pool as a research object which is characterized by high percentage of hydro power. And it is also the most mature hydro-dominated power market with a long-time trading experience of both spot and futures. On the other hand, China is the largest hydroelectricity generator in the world which account for $20.95 \%$ of the domestic capacity. The results from Nord Pool are supposed to be the most proper one. Besides, the model would be more suitable if China plans to launch electricity futures for renewable and using hydro as an underlying asset. Second, the Nordic region has been trading futures contracts since 1995 and has gone through several restructures. A worth-referring market is already set up. Besides, according to the findings of researching the price differential by Wimschulte (2010), the futures market in Nord Pool indicates an efficient pricing. So, Nord Pool has the most valuable market structure and mechanisms China need to learn from. Last but not least, the data Botterud used was from the initial stage of financial transactions in Nord Pool, which makes the results fit futures market of China at its early stage.

The model and results of Botterud are summarized as follow:

$$
\begin{aligned}
R P_{t, T}=\alpha_{0}+ & \alpha_{1} \times R E S_{t}+\alpha_{2} \times I N F D_{t, T}+\alpha_{3} \times \operatorname{CONSD}_{t, T}+\alpha_{4} \times P R I C E_{t}+\alpha_{5} \\
& \times V A R_{t}+\alpha_{6} \times S K E W_{t}+\varepsilon_{t}
\end{aligned}
$$

Where $R E S_{t}$ is the level of water reservoirs as a fraction of total capacity; E-mail: zhangyueno.8@163.com (Yue Zhang); arash.farnoosh@ifpen.fr (Arash Farnoosh). 
$I N F D_{t, T}$ and $C O N S D_{t, T}$ are respectively the total deviations of the water inflow and electricity consumption between day $\mathrm{t}$ and $\mathrm{t}+\mathrm{T}$ from long-term averages; $P R I C E_{t}$ is the average spot price in day $\mathrm{t}$ and $V A R_{t}$ and $S K E W_{t}$ are variance and skewness of the spot prices, respectively.

Table 1: Regression Results of Botterud's Model

\begin{tabular}{|c|c|c|c|c|c|c|c|}
\hline$\alpha_{0}$ & $\alpha_{1}\left(10^{3}\right)$ & $\alpha_{2}\left(10^{4}\right)$ & $\alpha_{3}\left(10^{4}\right)$ & $\alpha_{4}\left(10^{3}\right)$ & $\alpha_{5}\left(10^{6}\right)$ & $\alpha_{6}\left(10^{3}\right)$ & \multirow{3}{*}{$\begin{array}{c}\mathrm{R}^{2}=0.4 \\
4\end{array}$} \\
\hline $\begin{array}{c}\text { Constan } \\
\mathrm{t}\end{array}$ & $\begin{array}{c}\text { Reservoi } \\
\text { r }\end{array}$ & $\begin{array}{c}\text { Inflow } \\
\text { deviatio } \\
\text { n }\end{array}$ & $\begin{array}{c}\text { Consumptio } \\
\mathrm{n} \\
\text { deviation }\end{array}$ & $\begin{array}{c}\text { Averag } \\
\text { e } \\
\text { price }\end{array}$ & $\begin{array}{c}\text { Varianc } \\
\text { e } \\
\text { price }\end{array}$ & $\begin{array}{c}\text { Skewnes } \\
\text { s } \\
\text { price }\end{array}$ & \\
\hline $\begin{array}{c}0.21 * * \\
(3.38)\end{array}$ & $\begin{array}{c}-1.79 * * \\
(-2.63)\end{array}$ & $\begin{array}{c}-0.18 * * \\
(-6.16)\end{array}$ & $\begin{array}{l}0.81 * * \\
(7.73)\end{array}$ & $\begin{array}{c}-0.71 * \\
* \\
(-4.34)\end{array}$ & $\begin{array}{c}0.28 \\
(0.25)\end{array}$ & $\begin{array}{c}0.27 \\
(-0.044)\end{array}$ & \\
\hline
\end{tabular}

In terms of the specification of the futures contract, we summarize the features in Nord Pool and NYMEX as in the following table and apply them to the derivative market we proposed.

Table 2: Specifications of Electricity Futures Contract

\begin{tabular}{|c|c|}
\hline Contract size & $736 \mathrm{MWh}$ \\
\hline Tick size & $0.1 \mathrm{RMB} / \mathrm{MWh}$ \\
\hline Daily price limit & Within $\pm 5 \%$ of the last trading day settlement price \\
\hline Contract month & Every month \\
\hline Last trading day & X days before delivery month \\
\hline Margin & Physical Delivery \\
\hline Delivery method & Pach day in the delivery month \\
\hline Delivery grade & The transmission requirements (GBI2326-2000) \\
\hline Delivery day & Ealue \\
\hline
\end{tabular}

\section{Case Study}

E-mail: zhangyueno.8@163.com (Yue Zhang); arash.farnoosh@ifpen.fr (Arash Farnoosh). 
We take the energy environment of Taiwan Province of China as an example to study the price mechanism reformation, the establishment of the futures market, and the characteristics and functions of futures contracts. The electricity market in Taiwan is an ideal choice for our case study for several reasons: First, in terms of the electricity market, Taiwan does not have too much power transactions with inland provinces and neighboring countries. So, it is a relatively independent. Second, Taiwan and the mainland of China have similar power and energy components (Figure 4). And both are vigorously promoting the development of renewable energy. Last but not the least, Taiwan shares the same goals with the mainland to optimize the energy mix, reduce the emission and liberalize the market. Taiwan Power Company (Taipower) is a vertically integrated electricity utility company that is in charge of generation, transmission, distribution, and sales in Taiwan and its surrounding areas. Based on the above background, this section researches the establishment of electricity futures market in Taiwan Province, and simulates the futures prices under different pricing mechanisms.

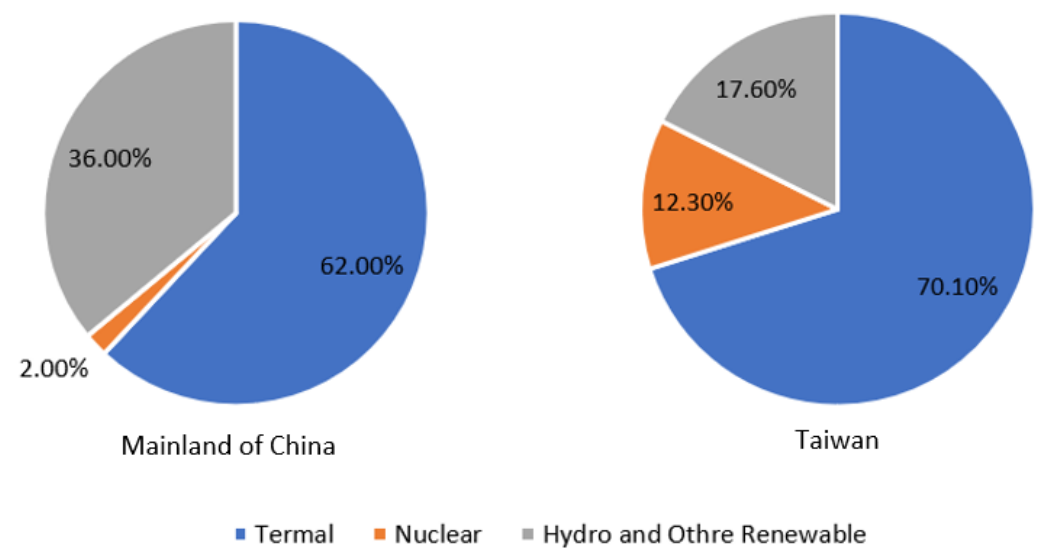

Figure 4: Comparison of Installed Capacity Between Mainland of China and Taiwan

E-mail: zhangyueno.8@163.com (Yue Zhang); arash.farnoosh@ifpen.fr (Arash Farnoosh).

Declarations of interest: none. 


\subsection{Forecast the Electricity Demand}

As we discussed in Section 3.1, a 3-layers BPNN model with inputs of historical demands, temperature, season and weekend is adopted to predict the hourly electricity demands in Taiwan. The data to train and to test the model are hourly power demands from $01 / 01 / 2016$ to $31 / 12 / 2017$ which includes 17544 samples. And $85 \%$ of that is used as input to the model for training while the remaining is used to test the accuracy (Jain et al., 2014). Figure 5 illustrates the comparison of actual power demand and predicted demand by BPNN. Except a few outliers, the forecasted results closely follow the real hourly demands.

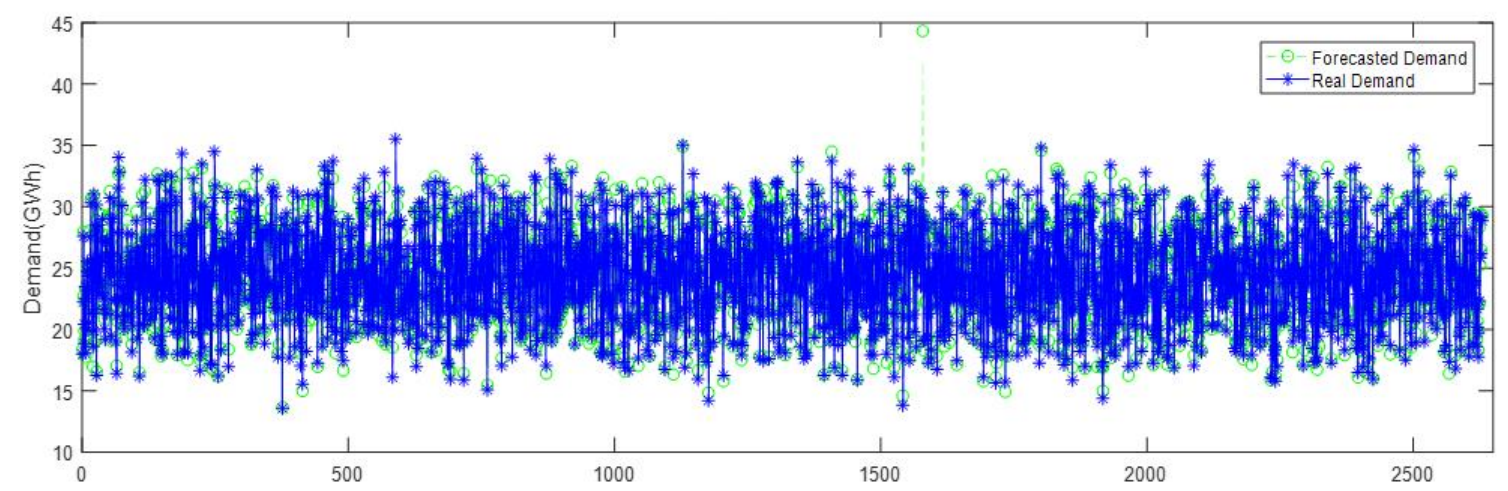

Figure 5: Testing Result of BPNN

And we adopt two parameters as the metrics to measure the errors. (Grolinger et al., 2016). One is the Mean Absolute Percentage of Error (MAPE) which describes the average absolute error as percentage and the other is Coefficient of Variance (CV) which expresses how much error varies with respect to the mean value of real demand. It could also represent the volatility of a group of number and will be used when we talk about risk level. 


$$
\operatorname{MAPE}=\frac{1}{N} \sum_{i=1}^{N} \frac{\left|y_{i}-\widehat{y}_{\imath}\right|}{y_{i}} \times 100
$$

Where $y_{i}$ is the actual demand; $\widehat{y}_{l}$ is the predicted demand and $\mathrm{N}$ is the number of test samples.

$$
\mathrm{CV}=\frac{\sqrt{\frac{1}{N-1} \sum_{i=1}^{N}\left(y_{i}-\widehat{y}_{l}\right)^{2}}}{\bar{y}} \times 100
$$

Where $\bar{y}$ is the mean of actual demand.

In terms of the BPNN model we use, MAPE is $1.80 \%$ while $\mathrm{CV}$ is $3.65 \%$. These two numbers in the paper lie in the high level of accuracy in terms of the existing power demand model (Yu and Xu, 2014; Hahn, 2009; Grolinger et al., 2016; Long et al., 2014; Rahman et al., 2016).

Therefore, the 3-layers BPNN model we proposed is well-trained and has a reliable ability to make an accurate prediction for hourly power demand in terms of Taiwan region. And the estimated demand in our case region will be used as a main input in the pricing mechanism of DSP.

\subsection{Volatile Wholesale Price Formation}

As we mentioned in Section 3.2, the volatility of wholesale prices is essential to the success of electricity contracts. So, the two pricing mechanisms we proposed are applied in the case region to replace the regulated prices.

\subsubsection{Demand-side Price (DSP)}

The propose of demand-side wholesale pricing model is to change the situation in a way that the power prices merely reflect the costs and margins but not mirror the balance in the market. It provides an alternative that is possible to let the demand-side 
have a greater bargaining power. The success of the model relies on mutual understanding of behaviors between the suppliers and consumers and the stability of the bidding system. The DSP in Taiwan can be calculated by formula (3) - (7) we mentioned in Section 3.2.1 and the case area satisfies the basic hypotheses: the demand of the region is under relatively low elasticity (with a coefficient of -0.07); we assume there are merely one power provider (Taipower) and one consumer (represents both industrial and residential); the supply and demand curves are known. Supply curve could be described by the accumulative generation and costs of different types of power and demand curve can be represented by a linear function with an elastic slope and the daily demand as intercept.

Figure 6 depicts the relationship between accumulative generation and costs of different electricity sources in Taiwan which can represent the overall supply curve of the sole provider-Taipower. It is apparent that coal and hydro, with relatively lower generation costs, satisfy the base load in the region. Natural gas and oil are used for peak load due to the high ramp-up and down rate. However, solar in Taiwan is underdeveloped with a cost of $8.52 ¥ / \mathrm{MWh}(1 ¥ \approx 0.1467 \$)$ and has barely no generation. And it is the renewable energy sources that need support and revolution. In terms of the supply curve formation, we adopt cubic equation to estimate it (Taylor and Majithia, 2000) which is also shown in Figure 6. 


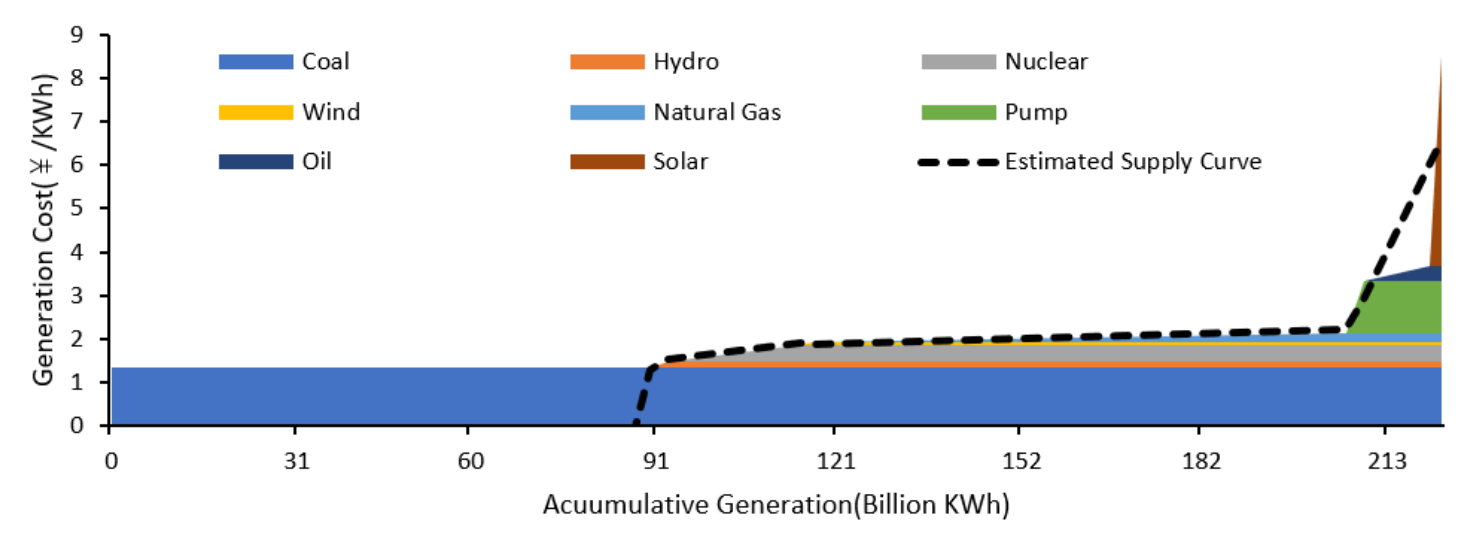

Figure 6: Supply Curve in Taiwan

Figure 7 shows the six-week daily demand-side prices from 01/01/2018 to 11/02/2018. We use CV (Coefficient of Variance) to measure the fluctuation so as to make it easier to compare. The DSP ranges from $2251.60 ¥ / \mathrm{MWh}$ to 3431.40 $¥ / \mathrm{MWh}$ and the CV reaches $9.41 \%$, which gives a volatile wholesale price. However, the DSP has a clear pattern that takes around seven days as a cycle. The prices peak at the middle of the weekdays and tend to be lower during weekends and the reason is that some commercial and industrial consumers will rest during Saturday and Sunday. Lower demands in weekend lead to lower price. Furthermore, the price follows the movement of the daily demand which means this pricing mechanism achieves the goal of considering consumers in the pricing process. Besides, the demand we input in this model is the predicted one that we get from the BPNN model (Section 5.1). So, for the renewable plants who would like to grasp the future trend of wholesale prices under demand-side pricing, it is the accuracy of the demand prediction that determines whether they could get a reliable price or not. 


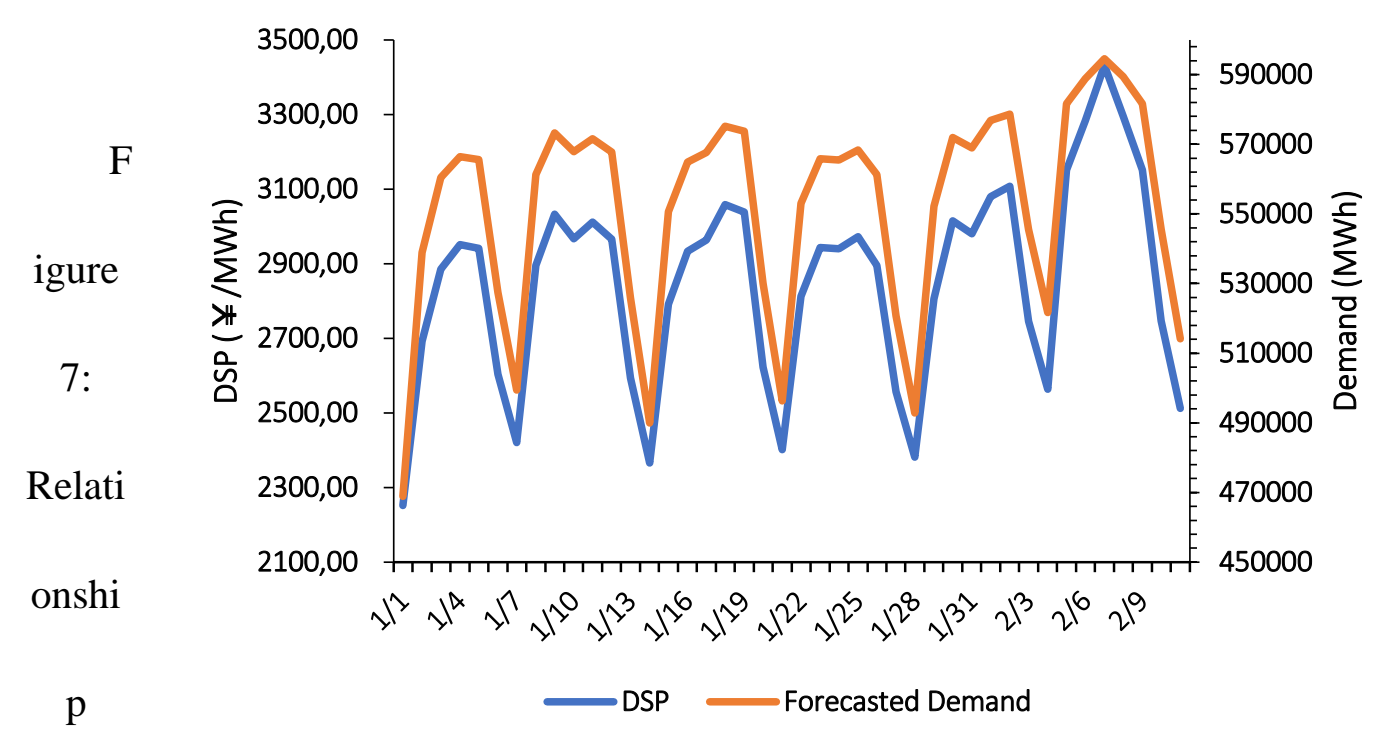

Between DSP and Forecasted Demand

\subsubsection{Opportunity Cost Price (OCP)}

OCP is an external price since its formation has nothing to do with the supply and demand in the wholesale market and its volatility is only determined by $\mathrm{CO} 2$ prices. The purpose of OCP is to give the conventional thermal plants an external cost (CO2 prices) to make the renewable energy comparable. So, in terms of the constant parameter $\gamma$ in formula (8), we assume that it equals to the average $\mathrm{CO} 2$ emission when we generate one unit of thermal electricity. The six-week OCP is presented in Figure 8 . The price ranges from $2177.81 ¥ / \mathrm{MWh}$ to $2194.02 ¥ / \mathrm{MWh}$ and it is less volatile with a CV of $0.21 \%$ when compared to DSP. 


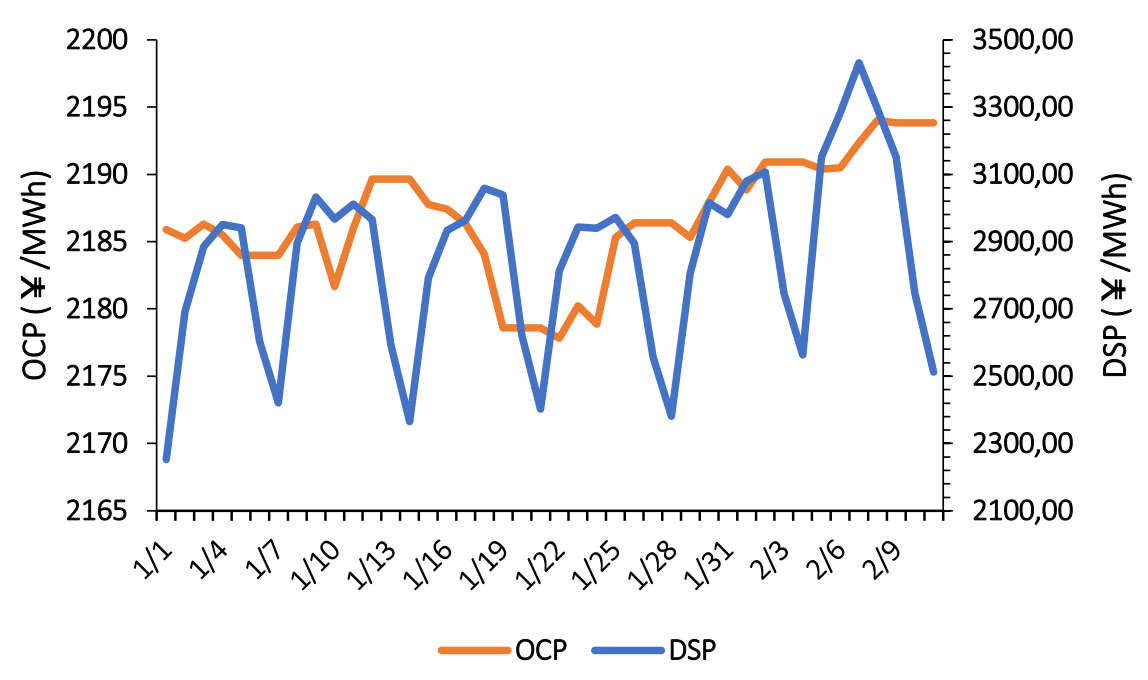

Figure 8: Comparison Between OCP and DSP

\subsection{Simulation of Electricity Futures}

As we mentioned in Section 4, an electricity derivative market is proposed in the case region. And the 13-year multi-factor econometric model of Nord Pool set up by Botterud et al. (2010) is adopted to simulate the futures contacts prices. Our analysis follows the model and is based on a daily futures contract with a maturity of 6 weeks. The model and results are shown in formula (13) and Table 1.

Botterud argues that hydro reservoir level influences both the short and long-term spot prices therefore the futures prices due to the high share of hydro power in Nord Pool. And hydro also plays a significant role in Taiwan. So, in this paper we also look for the similar relationship between the elements in the case area. Figure 9 shows the DSP we calculated along with the data of hydro storage in Taiwan, which confirms a clear negative relationship. The price apparently falls sharply in $22 / 1$ and 28/1 coinciding with an increase in reservoir level and vice-versa. This is because the reservoir level partly influences the power supply and therefore has an influence on the DSP. 


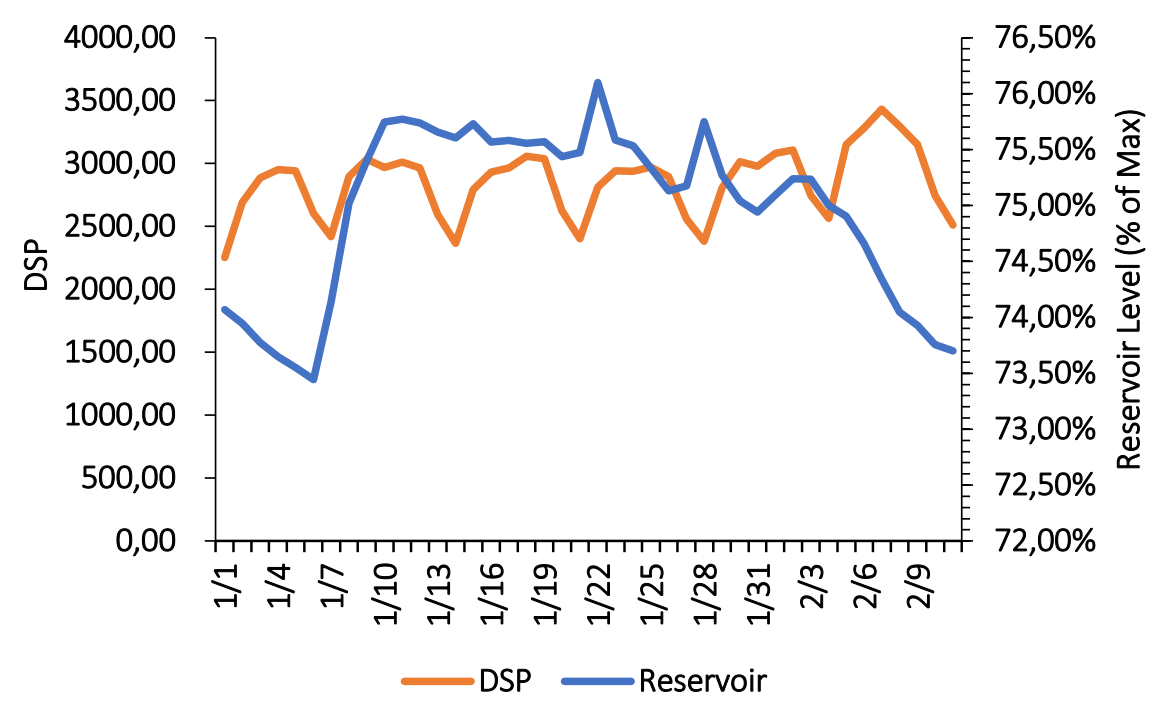

Figure 9: Relationship Between DSP and Reservoir Level in Taiwan

The same relationship can also be found between the reservoir level and OCP we got in 5.2.2 (Figure 10). However, the reason behind that may be explained from the point of $\mathrm{CO} 2$ trading: when the reservoir is at a high level, the power demand can be satisfied, the backup thermal power for high demand spike (like natural gas and oil) is less likely to be used and therefore there is less necessity to trade for the $\mathrm{CO} 2$ allowance. The $\mathrm{CO} 2$ price falls and the OCP decreases correspondingly.

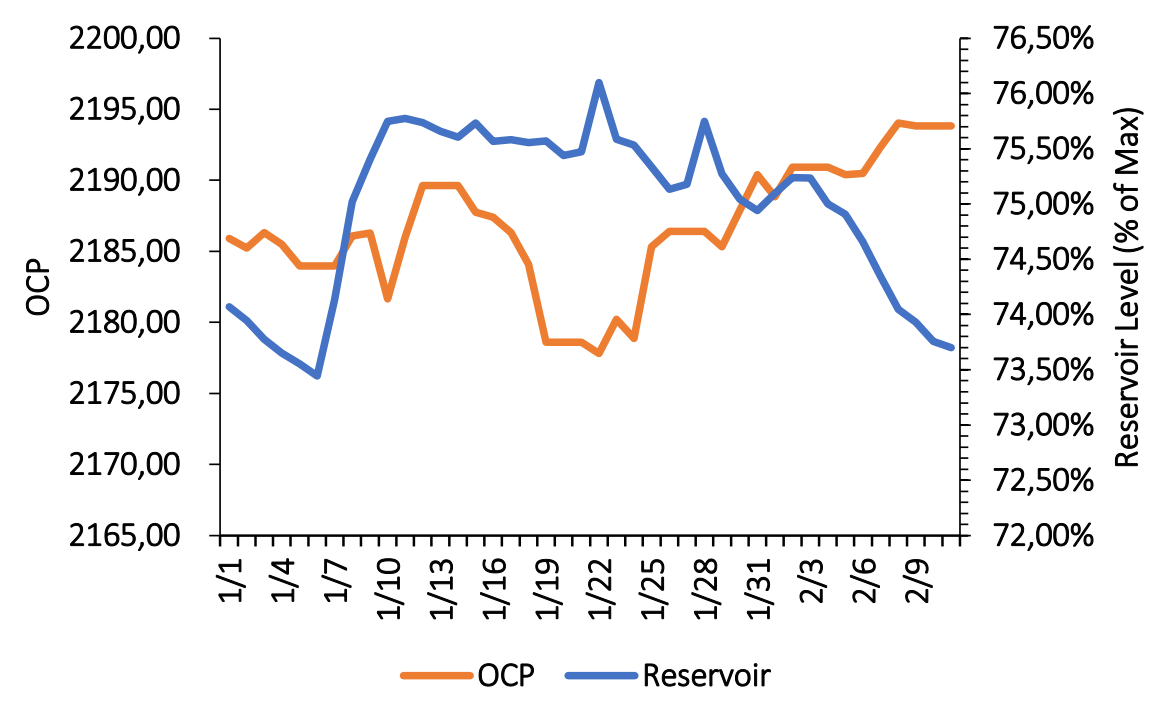

Figure 10: Relationship Between OCP and Reservoir Level in Taiwan E-mail: zhangyueno.8@163.com (Yue Zhang); arash.farnoosh@ifpen.fr (Arash Farnoosh). 
With a similar relationship between spot prices and reservoir as in Nord Pool, it is possible to simulate the futures prices using Botterud's model.

\subsubsection{Futures Prices under DSP}

As we discussed, the price of an electricity futures contract follows the expectation theory and one of its most important components is risk premium. So, we first use formula (13) and results in Table 1 to estimate the risk premiums in Taiwan under DSP. The detail of the risk premiums under DSP can be found in the Appendix

A. The risk premiums are positive over the 6-week holding period and they range from $6.2 \%$ to $26.61 \%$ with an increasing trend. The CV is high and increases as the contract is near to delivery. A positive risk premium indicates contango, which occurs when the electricity consumers are more prone to hedge than the power generators (Basu and Miffre, 2013). It leads to an excess demand for the electricity futures contracts and therefore, the futures prices would be higher than the spot prices. Market participants who hold the contracts would on average have negative returns too. Besides, the risk premium may increase when the demand sides enhance their degree of risk aversion to a greater extent than demand side. So, we can conclude that the futures market under DSP is dominated by consumers who are more risk adverse. And they tend to be more risk adverse when the expiration date is approaching.

The daily prices of the 6-week futures contract are simulated according to formula (9) and presented in Figure 11. Due to the positive risk premium, the futures prices exceed the demand-side spot prices. And it is less volatile than the wholesale price with a $\mathrm{CV}$ of $4.5 \%$. Besides, the futures prices we simulated in Taiwan follow E-mail: zhangyueno.8@163.com (Yue Zhang); arash.farnoosh@ifpen.fr (Arash Farnoosh). 
the trend of demand-side price with a correlation $\left(\mathrm{R}^{2}\right)$ of $92.75 \%$ and it proves that both the spot prices and reservoir level have significant impact on the futures prices. However, as we discussed in Section 2, the spot and futures prices of electricity are not as binding as other commodities because of its unique characteristic. The futures price does not approach the spot price at the end of the maturity and the basis is also more fluctuating than other commodities.

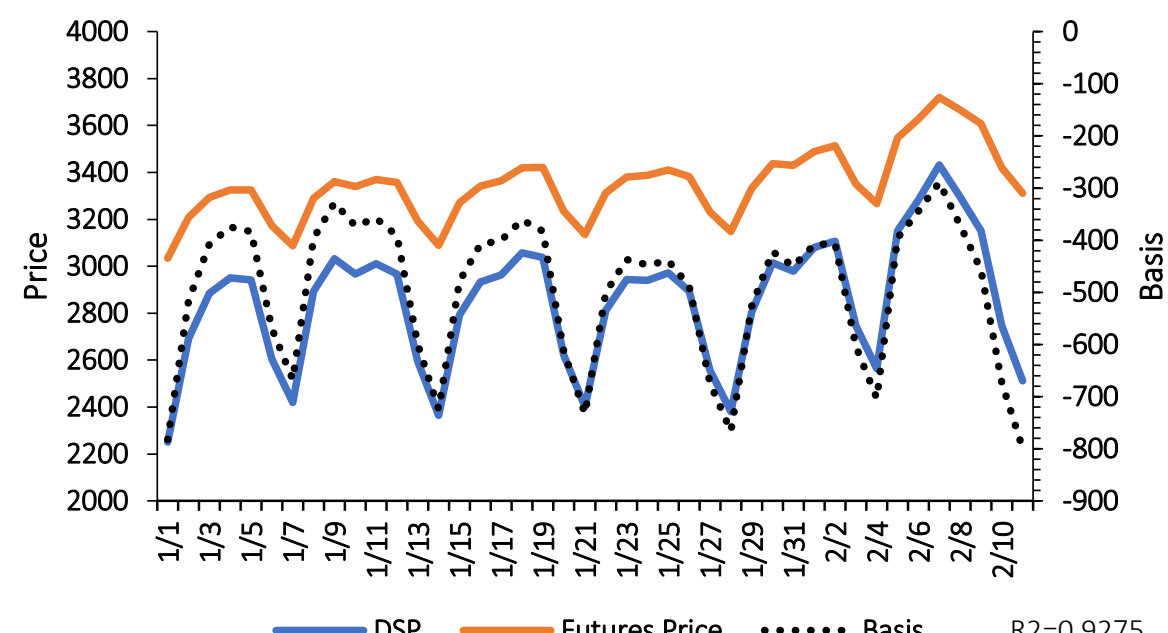

Figure 11: Futures Prices under DSP

\subsubsection{Futures Prices under OCP}

The risk premium under OCP is also shown in the Appendix A and it share similar attributes as the DSP scenario. Nevertheless, it is less volatile with a CV of $24.58 \%$ and ranges from $5.04 \%$ to $11.68 \%$. Figure 12 shows the futures prices under this scenario. Different from the DSP scenario, the futures prices under OCP are more fluctuating than the corresponding spot prices (OCP). And the risk premium has a more apparent increased trend which lead to a greater basis when the expiration day approaches. The potential reason could be ascribed to the non-storability of electricity E-mail: zhangyueno.8@163.com (Yue Zhang); arash.farnoosh@ifpen.fr (Arash Farnoosh). 
which make the users more adverse to the price risk when the power is about to deliver.

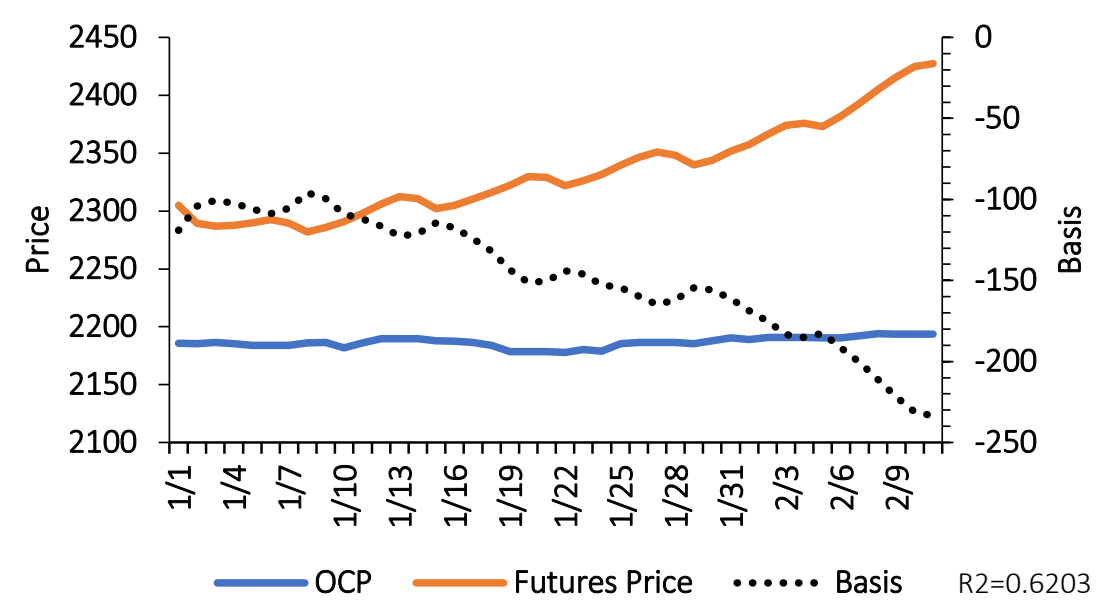

Figure 12: Futures Prices under OCP

Figure 11 and Figure 12 also show the basis in two different futures markets. It is obvious that in both pricing scenarios the basis is not steady which can be found in Table 3. Since the price of a futures contact can be described by the spot price and the storage cost, the fluctuating basis may partly due to the uneconomic holding of electricity. Another possible reason may be the mismatch of the underlying asset (hydro power) and hedged risk (all kinds of power). The volatile basis brings unexpected basis risk to the hedgers in the market. It determines the actual risk and revenue in the hedging process and needed to be treated carefully.

Table 3: Statistics of Basis under Two Pricing Mechanisms

\begin{tabular}{c|cc}
\hline Pricing Scenario & DSP & OCP \\
\hline Max & -289.125 & -95.9665 \\
Min & -799.19 & -233.447
\end{tabular}

E-mail: zhangyueno.8@163.com (Yue Zhang); arash.farnoosh@ifpen.fr (Arash Farnoosh). 


\begin{tabular}{c|ll} 
Mean & -496.46 & -147.51 \\
CV & $-28.24 \%$ & $-25.54 \%$ \\
\hline
\end{tabular}

The comparison between the futures prices under DSP and OCP can be found in Figure 13. The futures prices simulated under two different spot pricing mechanisms have similarities: they both exceed the spot prices and increase as the contract approaches the delivery date. However, the futures price under DSP is more volatile and has a closer correlation with spot price. And with a much higher spot price, the futures price formed by DSP exceeds the price under OCP scenario. Since the two futures prices are simulated by the same model and data except the spot prices, it is easy to draw the conclusion that the spot price (formulated whether by the power market itself or external market) has a strong influence on the futures contract.

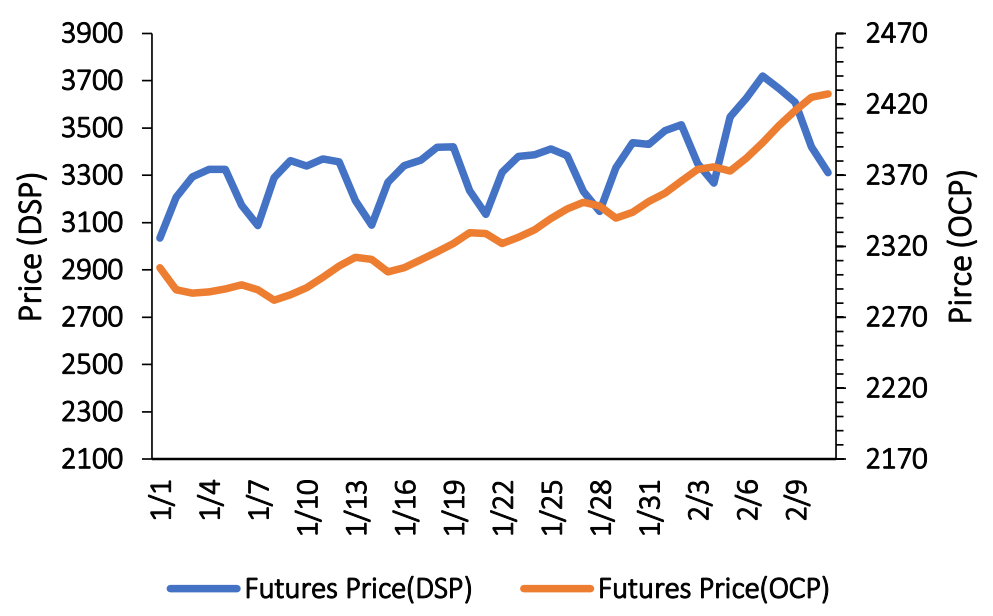

Figure 13: Comparison of Future Prices Under Two Pricing Mechanisms

\subsection{Operational Strategy with Futures}

Renewable energies are strongly promoted as environmentally friendly powers both in Taiwan and other parts of China. But due to the high cost and unstable supply, they have difficulties to survive without subsidies. So, they are the participates in urgent need of hedging in the power market to guarantee their own competitiveness. E-mail: zhangyueno.8@163.com (Yue Zhang); arash.farnoosh@ifpen.fr (Arash Farnoosh). 
Among all renewable energies, wind is the most mature and promising one to compete freely with thermal power. So, in this section, we will study the operational strategy and its corresponding revenue and risk for a wind plant in the case region.

Suppose Generator A is a wind power plant located in Taiwan and only provides electricity generated by its own turbines to Taipower. Its generation cost is at the average level in Taiwan, which is $1910 ¥ / \mathrm{MWh}$. It takes a constant share in the market $-1 \%$ of the total demand in Taiwan and we assume that the generation of plant A is stable enough to satisfy the daily demand. Besides, generator A uses the above models and methods we proposed to make decision in terms of its hedging activity in the futures markets.

\subsubsection{Revenues of Plant A under Different Pricing Mechanisms}

Figure 14 analyzes the revenues of wind plant A under different pricing mechanisms. It should be noticed that $\mathrm{CV}$ of revenue represents the risk of generator. We can find that when the wholesale price of wind power is regulated and subsidized by government (feed-in tariff, basic scenario), the revenue is around 4 million Yuan per day and is relatively stable with a $\mathrm{CV}$ of $5.44 \%$. And when the demand-side pricing is applied, the average revenue of plant $\mathrm{A}$ is greatly improved by $16.78 \%$ but the risk also increases up to $32.47 \%$ (5 times higher than basic scenario). Nevertheless, the profit of the generator under OCP is merely around 1.6 million which is decrease by $66.19 \%$ compare to basic scenario. And the $\mathrm{CV}$ is $5.91 \%$ which is similar to the situation when feed-in tariff is applied. The reason is that opportunity cost price is derived by the sum of thermal power price and the $\mathrm{CO} 2$ price which are both at a low E-mail: zhangyueno.8@163.com (Yue Zhang); arash.farnoosh@ifpen.fr (Arash Farnoosh). 
level as well as stable. So, the electricity futures may be used by renewable plant A for different purpose under different pricing scenarios: it is mainly used as a tool to stabilize the revenue under DSP (hedger) and is adopted to enhance profit under OCP (speculator).

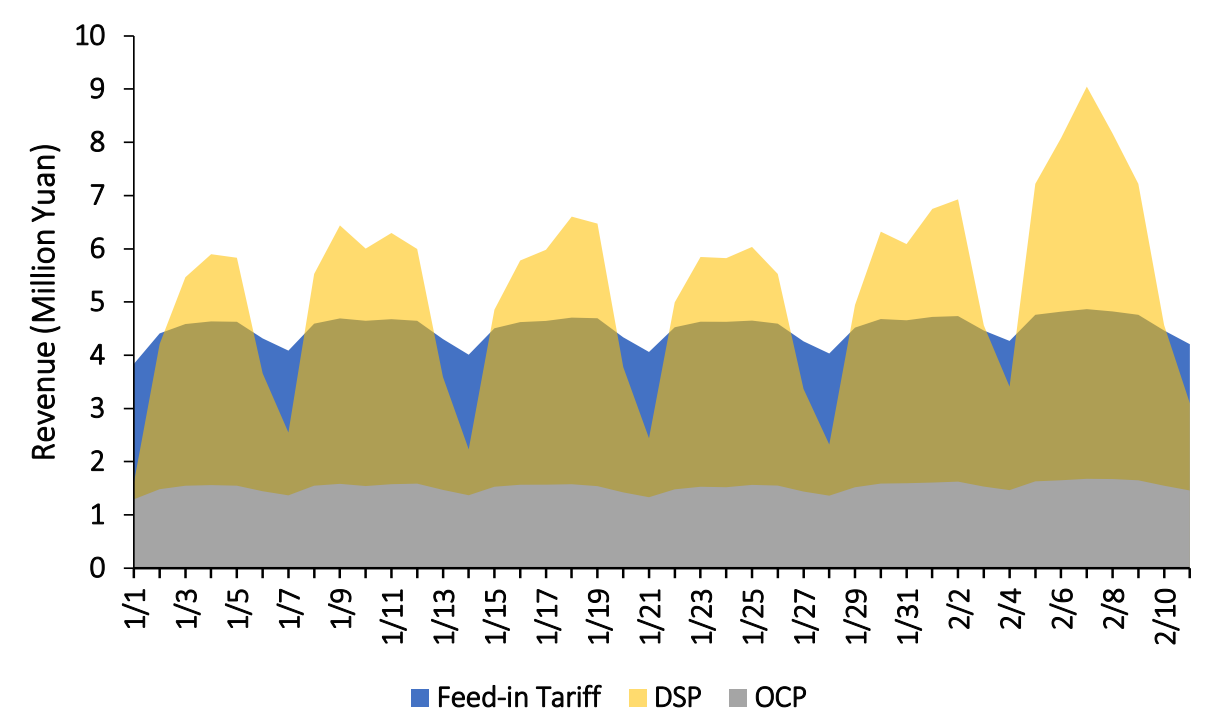

Figure 14: Revenues of Plant A Under Different Pricing Mechanisms

\subsubsection{Optimal Hedging Ratio}

We adopt the delta hedging strategy to find the optimal ratio as we mentioned in Section 3.4. Since the price series may exhibit significant heteroskedasticity in the errors of estimation, the White correction is implemented to fix it. Table 4 details the regression results of formula (11) for the 6-week futures contract we proposed. We can see that in both pricing scenarios, the hedge ratios $(\beta)$ are significant with less than 5\% p-values. However, the optimal hedge ratios under the two pricing mechanisms are totally different. When the DSP is adopted in the power market, the hedge ratio reaches 2.21 , which means the volatility of the spot price is more than 2 times than that of the futures price. So, the plant needs to use more futures position than spot position to hedge but it will also increase the cost of hedging accordingly. 
While under OCP, the ratio is under 1. Furthermore, according to Hull (2001), the hedge effectiveness can be described by the $\mathrm{R}^{2}$. From this point of view, though with higher hedging cost, the hedging performance under DSP may be better than the other pricing mechanism. What should be noticed is that the hedge ratio is not constant, it may change according to the time, different contracts etc. And the optimal contracts used for hedging can be calculated by formula (12).

Table 4: Regression Details of Optimal Hedge Ratio

\begin{tabular}{c|ccc}
\hline Pricing Mechanism & $\beta$ & P-value & $\mathrm{R}^{2}$ \\
\hline DSP & 2.21 & 0 & 0.99 \\
OCP & 0.8 & 0.05 & 0.55 \\
\hline
\end{tabular}

\subsubsection{Hedging Strategy under DSP}

Due to the high risk and high yield faced by the power plant under DSP, electricity futures will tend to be used as a hedging tool in this scenario. The traditional hedging method to manage the risks is to do the opposite operations in the electricity spot market. So, for the wind generator A, the hedging strategy should be short the futures contracts according to the predicted power demand and long the same amount of the same contract before the expiration day to complete a hedging operation.

As we discussed, the futures price under DSP have a regular pattern, which takes 7 days a week as a cycle and usually hits the peak at the end of each weekdays. Without any doubt, it ought to be the best time to short the electricity futures. The only remaining problem is how long should plant A holds the contracts so as to reduce the fluctuations and even enhance the revenue. Figure 15 may answer the question E-mail: zhangyueno.8@163.com (Yue Zhang); arash.farnoosh@ifpen.fr (Arash Farnoosh). 
quiet well. It shows the simulation results of daily settlement of the futures market in which the wind plant A shorts the futures contract at six different entry contracts. Short0104 represents the daily settlement result of A after shorting the electricity futures contract on January 4. Besides, the number of contracts it short is calculated by the $\beta$ and the forecasted prices and demand by BPNN. We could find out that after opening a short position in the futures market, the daily settlement will be positive in the next few days and decline to negative and circulate. Furthermore, the net profit in this derivative market will decrease with the holding time. For example, Short0104's profit in the first cycle peaked at 2.11 million yuan, while the maximum profit in the second cycle fell to 2.08 million yuan. The reason is that the profitability of short position decreases and the price of futures contract rises as the expiration date approach. Therefore, the best time to hedge the short position in the futures market should be around three days after entering the futures short contract. Under this strategy, wind plants A needs to hedge six times in the 6-week period. 


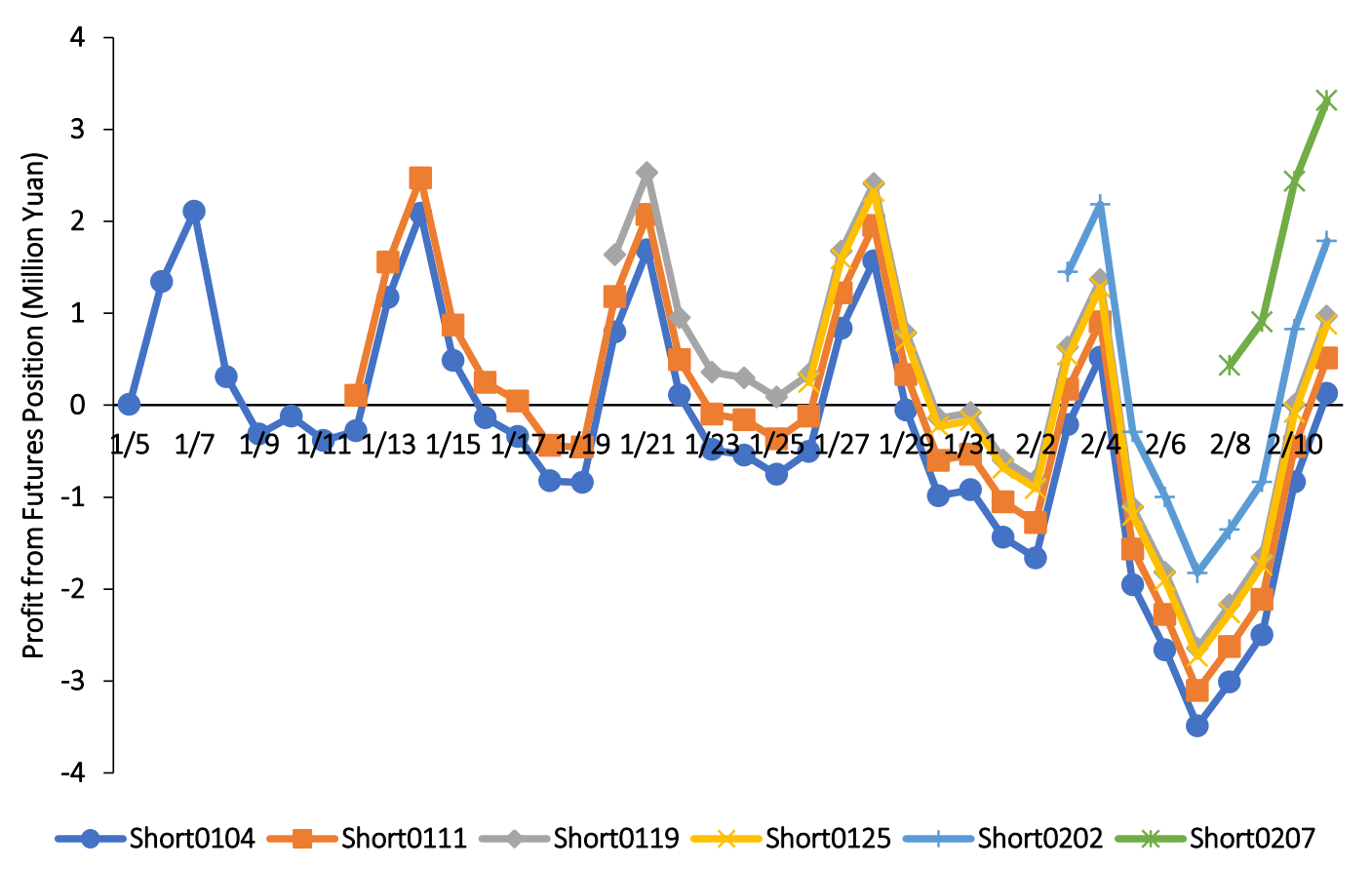

Figure 15: Daily Settlement under Different Position-opening Time

Figure 16 compares the daily revenues before and after the short-term hedging strategy we proposed. The usage of the futures contracts compensates the profit valleys of generator $\mathrm{A}$ and hence reduces the volatility ( $\mathrm{CV}$ decreases by $25 \%$ ). Besides, this method also enhances the total earning by $6.74 \%$. The details of the revenue are shown in Table 5.

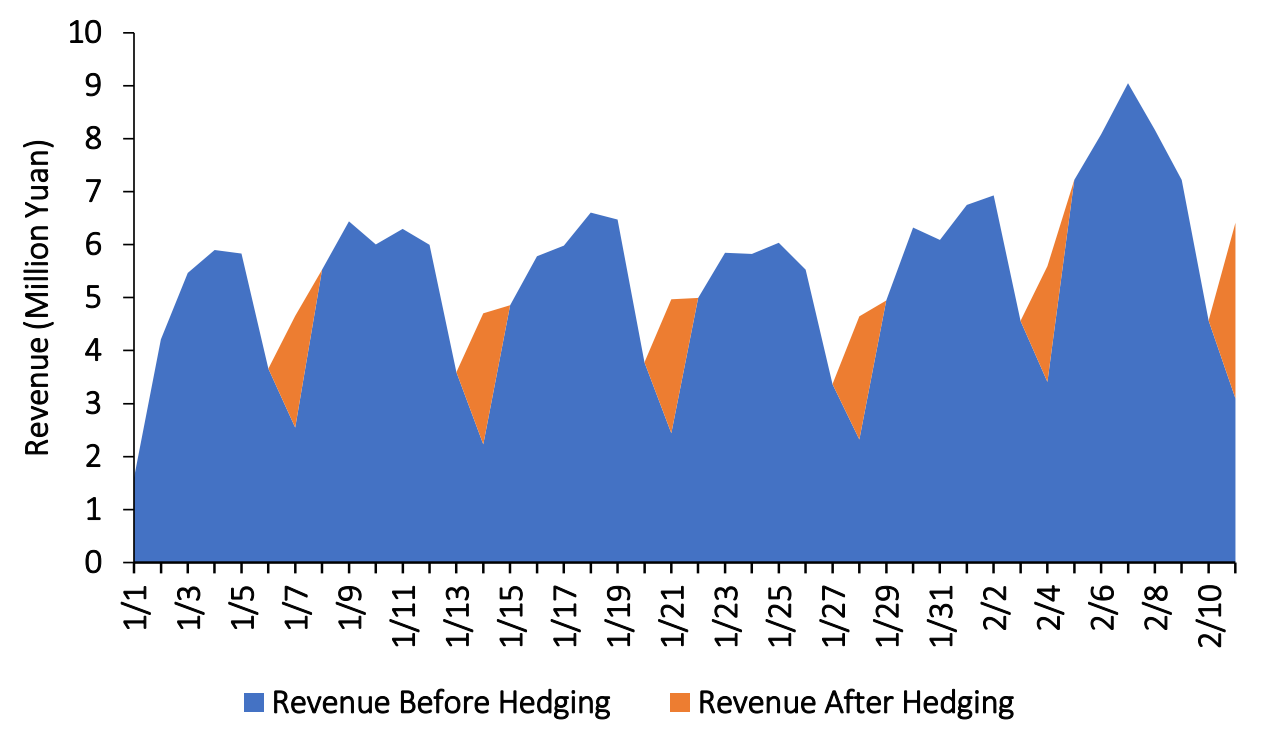

E-mail: zhangyueno.8@163.com (Yue Zhang); arash.farnoosh@ifpen.fr (Arash Farnoosh).

Declarations of interest: none. 
Figure 16: Comparison of Daily Revenue Before and After Hedging

Under DSP, the spot price, futures price and the contracts used to hedge are all influenced by the forecasted demand. Therefore, we also study the importance of accuracy of predicted demand to the effectiveness of futures hedge. With a random error of $5 \%$, the risk (CV) will increase by $1.42 \%$ and total revenues of A will change by $1.9 \%$ compare to the perfect forecast (Table 5 ). So, the success of A's futures hedge is determined by type of model they used to predict their daily demand and its accuracy.

Table 5: Statistics of Plant A's Revenue under Different Scenarios

\begin{tabular}{cccc}
\hline Scenario & Before Hedging & $\begin{array}{c}\text { After Hedging } \\
\text { (Perfect Forecast) }\end{array}$ & $\begin{array}{c}\text { After Hedging } \\
\text { (With 5\% Error) }\end{array}$ \\
\hline $\begin{array}{c}\text { Total Revenue } \\
\text { (Million Yuan) }\end{array}$ & 221.52 & 236.46 & 232.08 \\
Mean (Million Yuan) & 5.27 & 5.63 & 5.53 \\
CV & $32.47 \%$ & $24.33 \%$ & $25.75 \%$ \\
\hline
\end{tabular}

\subsubsection{Speculation Strategy under OCP}

As we discussed in 5.4.1, electricity futures may be mainly used as a tool to enhance the revenue due to the lower spot price and volatility under OCP. So, under this price scenario, plant $\mathrm{A}$ is more like a speculator rather than a hedger. And the objective of $\mathrm{A}$ is to gain as much profit as possible from the futures market without creating more risk.

In this pricing scenario, the risk premium increases as the contract approaching its expiration which leads to an overall increasing futures price. So, a better speculation strategy for the wind generator A is to long the electricity futures contract 
at the beginning and hold it until the last trading day. This strategy is totally different from the traditional hedging method for the supplier and asks for a reliable grasp of the trend of futures price. If the price falls instead of the upside trend we predicted, plant A will either suffer great loss in the financial market or be forced to execute the contract and obtain electricity at an undesirable price.

To make the results comparable, we assume the cost and specifications of the contracts is the same in both sceanrios. And A is supposed to have the same cashflow that can be used to the futures market. So, it will long exactly number of contracts under OCP as it does in the whole 6-week period under DSP. The total revenue A could get from the speculation is 7.7 million yuan (it is less than the 14.92 million yuan it could win from the hedging strategy in DSP scenario). Besides, the total profit of A from both spot and futures markets is 71.85 million yuan and it is $12 \%$ higher than the situation before speculation. However, the profit is still less than that under DSP (236.46) and feed-in tariff (189.69). Hence, under OCP, a renewable generator needs more capital to speculate in the financial market in order to compensate its profit loss. Nevertheless, the risk will become greater and need to be treated more carefully. And therefore, when the OCP is implemented, financial market will be a significant component and even as important as the wholesale activity.

\section{Conclusions and Implications}

The goals of this paper are to introduce electricity futures contracts into electricity market of China and simulate their prices to quantitatively analyze the value and significance for renewable power plants.

E-mail: zhangyueno.8@163.com (Yue Zhang); arash.farnoosh@ifpen.fr (Arash Farnoosh). 


\subsection{Main Conclusions}

We did a case study on the electricity market in Taiwan Province of China and the results show as follows:

First, the performance of futures price is closely related to the pricing mechanism of wholesale market: under DSP, the futures price is higher with a stronger volatility; Under OCP, futures prices are at lower range but more stable. In both scenarios, the futures market is contango, and the futures price does not gradually approach to the spot price around the expiration date.

Second, two different pricing mechanisms have their own pros and cons for renewable plants: when using DSP, wind plant A could win $16.78 \%$ higher income than feed-in tariff scenario in 6 weeks. Meanwhile, A also faces greater risks (the volatility of earnings increased by 5 times). Under OCP, revenue of A decreases by $66.19 \%$ with a very low risk.

Finally, the operational strategy research of A in futures market shows that the reasonable use of the contract could improve the revenue and reduces risk. The increases in revenue are $6.74 \%$ and $12 \%$ in two scenarios.

\subsection{Implications}

\subsubsection{For Government}

Since a volatile spot price is essential for the establishment of derivative market, a pricing mechanism revolution is necessary and the government should choose a suitable one according to market environment.

The DSP can give a certain bargaining power to the consumer and reflect the E-mail: zhangyueno.8@163.com (Yue Zhang); arash.farnoosh@ifpen.fr (Arash Farnoosh). 
supply and demand balance in the market. But the wholesale prices and futures prices under DSP are more volatile and it will make the fragile renewable plants face greater uncontrollable market risk in the initial stage of electricity futures market. OCP creates necessary condition for the establishment of futures market with relatively stable risks, but it brings a significant reduction in renewable power plants' revenue. Therefore, we believe that government should adopt OCP in the early stage of the reform, so that the market risk can be controlled at the beginning of reform. However, due to the huge revenue losses of renewable plants under OCP, the government could gradually reduce subsidies and increase external costs like $\mathrm{CO} 2$ price to guarantee the development of them. And after a few years of operations and when the market becomes more mature, DSP should be adopted to bring more competition to market. This step by step revolution will also allow market participants have sufficient time to get familiar with the characteristics and functions of futures contract in a stable environment.

Moreover, the government should also pay attention to the regulations of futures contract and market. The experience from other mature market may be drawn while the localization could not be neglected so as to make it more suitable for market in China.

\subsubsection{For Renewable Power Plant}

The case of plant A implies the appropriate usage of futures contract under both pricing scenarios can smooth and increase its revenue. However, the contracts have their own roles in different scenarios, ranging from hedge to speculation. So, for E-mail: zhangyueno.8@163.com (Yue Zhang); arash.farnoosh@ifpen.fr (Arash Farnoosh). 
renewable plants, they should adjust their strategies according to the status in market. When the wholesale price is more volatile with the possibility of more revenue and loss at the same time (DSP), the futures should perform as a hedging tool to stabilize the risk. But if the wholesale price is lower with more stability (OCP), it should be used as an speculation tool to gain more profit for the plant. Nevertheless, in any case, as a participant in electricity futures market, renewable plants should process the ability to develop a reasonable strategy based on accurate predictions of futures price and their spot positions. It should also be noticed that under the DSP, the effect of futures hedge is greatly impacted by the prediction accuracy. So, when DSP is dominated in the wholesale market, it is the demand forecast model that a renewable plant uses that decides the success of its strategies. And the BPNN model we propose may be a good alternative.

At the end we should emphasize that there are limitations in this study. First, the cost of the futures contract is not considered due to the unavailability of data. Second, since the paper mainly focus on simulating the price and function of futures contracts in China, no discussion concerning the intrinsic influence of the spot pricing mechanism on futures prices is carried out. These shall be taken in to account and overcome in the future research.

\section{Acknowledgement}

This research did not receive any specific grant from funding agencies in the public, commercial, or not-for-profit sectors. And we would like to take the opportunity to thank those people who have provided helpful suggestions during the 
research. We also gratefully acknowledge the editors for kind help and the anonymous reviewers for their beneficial comments and encouragement. 


\section{Reference}

Ardakani, F.J., Ardehali, M.M., 2014. Long-term electrical energy consumption forecasting for developing and developed economies based on different optimized models and historical data types. Energy 65, 452-461.

Basu, D., Miffre, J., 2013. Capturing the risk premium of commodity futures: The role of hedging pressure. Journal of Banking \& Finance 37, 2652-2664.

Bazilian, M., Mai, T., Baldwin, S., Arent, D., Miller, M., Logan, J., 2014. Decision-making for High Renewable Electricity Futures in the United States. Energy Strategy Reviews 2, 326-328.

Benth, F.E., Koekebakker, S., 2008. Stochastic modeling of financial electricity contracts is. Energy Economics 30, 1116-1157.

Bessembinder, H., Lemmon, M.L., 2002. Equilibrium Pricing and Optimal Hedging in Electricity Forward Markets. Journal of Finance 57, 1347-1382.

Billio, M., Casarin, R., Osuntuyi, A., 2017. Markov switching GARCH models for Bayesian hedging on energy futures markets. Energy Economics.

Black, D.G., 1986. Success and Failure of Futures Contracts: Theory and Empirical Evidence. York University Monograph.

Botterud, A., Bhattacharyya, A.K., Ili, M., 2002. Futures and spot prices - an analysis of the Scandinavian electricity market. Proceedings of.

Botterud, A., Kristiansen, T., Ilic, M.D., 2010. The relationship between spot and futures prices in the Nord Pool electricity market. Energy Economics 32, 967-978.

Chandra, B., Sharma, R.K., 2015. Fast Learning in Deep Neural Networks. 
Neurocomputing 171, 1205-1215.

Douglas, S., Popova, J., 2008. Storage and the electricity forward premium is. Energy Economics 30, 1712-1727.

Dufour, J.M., Cheng, H., 2008. The New Palgrave Dictionary of Economics Online. Palgrave Macmillan,.

Edwards, F.R., Canter, M.S.C., 1995. The collapse of Metallgesellschaft: Unhedgeable risks, poor hedging strategy, or just bad luck? Journal of Futures Markets 15, 211 264.

Fama, E.F., French, K.R., 1987. Commodity Futures Prices: Some Evidence on Forecast Power, Premiums, and the Theory of Storage. Journal of Business 60, 55-73.

Fanelli, V., Maddalena, L., Musti, S., 2016. Modelling electricity futures prices using seasonal path-dependent volatility. Applied Energy 173, 92-102.

Frestad, D., 2012. Liquidity and dirty hedging in the Nordic electricity market. Energy Economics 34, 1341-1355.

Geman, H., Vasicek, O., Vasicek, O.A., n.d. Plugging into Electricity. John Wiley \& Sons, Inc.

Giovanna Zanotti, Giampaolo Gabbib, Manuela Geranio, 2010. Hedging with futures: Efficacy of GARCH correlation models to European electricity markets. Journal of International Financial Markets, Institutions and Money 20, 135-148.

Grolinger, K., L'Heureux, A., Capretz, M.A.M., Seewald, L., 2016. Energy Forecasting for Event Venues: Big Data and Prediction Accuracy. Energy \& Buildings 112, 222233.

E-mail: zhangyueno.8@163.com (Yue Zhang); arash.farnoosh@ifpen.fr (Arash Farnoosh). 
Hahn, H., 2009. Electric load forecasting methods: Tools for decision making. European Journal of Operational Research 199, 902-907.

He,Chuan, 2010. Research on Functions of Electricity Futures Market. Zhejiang University.

Huisman, R., Kiliç, M., 2015. Time variation in European carbon pass-through rates in electricity futures prices. Energy Policy 86, 239-249.

Huisman, R., Kilic, M., 2012. Electricity Futures Prices: Indirect Storability, Expectations, and Risk Premiums is. Energy Economics 34, 892-898.

Hull, J.C., 2001. Options, futures, and other derivatives /. Tsinghua University Pres.

Jain, R.K., Smith, K.M., Culligan, P.J., Taylor, J.E., 2014. Forecasting energy consumption of multi-family residential buildings using support vector regression: Investigating the impact of temporal and spatial monitoring granularity on performance accuracy. Applied Energy 123, 168-178.

Kallabis, T., Pape, C., Weber, C., 2015. The plunge in German electricity futures prices Analysis using a parsimonious fundamental model. Social Science Electronic Publishing 95, 280-290.

Karakatsani, N.V., Bunn, D.W., 2005. Diurnal Reversals of Electricity Forward Premia. London Business School.

Kazanasmaz, T., Günaydin, M., Binol, S., 2009. Artificial neural networks to predict daylight illuminance in office buildings. Building \& Environment 44, 1751-1757.

Kialashaki, A., Reisel, J.R., 2013. Modeling of the energy demand of the residential sector in the United States using regression models and artificial neural networks. 
Applied Energy 108, 271-280.

Kolos, S.P., Ronn, E.I., 2008. Estimating the commodity market price of risk for energy prices. Energy Economics 30, 621-641.

Kroner, K.F., Sultan, J., 1993. Time Varying Distributions and Dynamic Hedging with Foreign Currency Futures. Journal of Financial \& Quantitative Analysis 28, 535551.

Lai, Y.S., Sheu, H.J., Lee, H.T., 2017. A Multivariate Markov Regime-Switching HighFrequency-Based Volatility Model for Optimal Futures Hedging. Journal of Futures Markets 37.

Lee, H.T., Yoder, J.K., Mittelhammer, R.C., Mccluskey, J.J., 2010. A random coefficient autoregressive Markov regime switching model for dynamic futures hedging. Journal of Futures Markets 26, 103-129.

Lien, D., Tse, Y.K., Tsui, A.K.C., 2002. Evaluating the hedging performance of the constant-correlation GARCH model. Applied Financial Economics 12, 791-798.

Liu,Feng, 2005. Research On Application of Electic Future in Chinese Electirc Power Market. Wuhan University.

Long, H., Zhang, Z., Su, Y., 2014. Analysis of daily solar power prediction with data-driven approaches. Applied Energy 126, 29-37.

Longstaff, F.A., Wang, A.W., 2004. Electricity Forward Prices: A High-Frequency Empirical Analysis. Journal of Finance 59, 1877-1900.

Lucia, J.J., Torró, H., 2011. On the risk premium in Nordic electricity futures prices. International Review of Economics \& Finance 20, 750-763.

E-mail: zhangyueno.8@163.com (Yue Zhang); arash.farnoosh@ifpen.fr (Arash Farnoosh).

Declarations of interest: none. 
Lucia, J.J., Torró, H., 2008. Short-Term Electricity Futures Prices: Evidence on the Time-Varying Risk Premium. Working Papers Serie Ec.

Lui, W., 2001. The Mismatch between Futures and Spot Prices: Why the Electricity Futures Contracts Are Failing. University of the Redlands.

Miller, T, Thompson, A, 2002. On the Risk-Shifting Capabilities of the Electricity Futures Market. University of Missouri-Columbia.

Moulton, J.S., 2005. California electricity futures: the NYMEX experience. Energy Economics 27, 181-194.

Panapakidis, I.P., 2016. Clustering based day-ahead and hour-ahead bus load forecasting models. International Journal of Electrical Power \& Energy Systems $80,171-178$.

Rahman, M.N., Esmailpour, A., Zhao, J., 2016. Machine Learning with Big Data An Efficient Electricity Generation Forecasting System is. Big Data Research 5, 9-15. Roques, F., 2008. Analytical Methods for Energy Diversity and Security - Portfolio Optimization in the Energy Sector: A Tribute to the work of Dr. Shimon Awerbuch. Scwheppe, F.C., Caraminis, M.C., Tabors, R.O., Bohn, R.E., 1997. Spot Pricing of Electricity. Kluwer International 144, 399-405.

Taylor, J.W., Majithia, S., 2000. Using combined forecasts with changing weights for electricity demand profiling. Journal of the Operational Research Society $51,72-$ 82.

Treslong, A.B.V., Huisman, R., 2009. A comment on: Storage and the electricity forward premium. Energy Economics 32, 321-324.

E-mail: zhangyueno.8@163.com (Yue Zhang); arash.farnoosh@ifpen.fr (Arash Farnoosh).

Declarations of interest: none. 
Weron, R., Zator, M., 2014. Revisiting the relationship between spot and futures prices in the Nord Pool electricity market. Energy Economics 44, 178-190.

Wimschulte, J., 2010. The futures and forward price differential in the Nordic electricity market. Energy Policy 38, 4731-4733.

Yu, F., Xu, X., 2014. A short-term load forecasting model of natural gas based on optimized genetic algorithm and improved BP neural network. Applied Energy 134, 102-113.

Zhang, Shao Hua, 2001. Theoretical Studies on Risk Modeling of Forward Contracts in Electricity Markets. Shanghai University.

Zhang,Cai Qing, 2004. The Formation Mechanism of Electricity Price and Price2f ixing Model Based on Demand Side. East China Electric Power 32, 4-6. 
Appendix A: Statistics of Risk Premium and Futures Prices

\begin{tabular}{|c|c|c|c|c|}
\hline Date & RP under DSP & Futures Price under DSP & $\mathrm{RP}$ under $\mathrm{OCP}$ & Futures Price under OCP \\
\hline $2018 / 1 / 1$ & 0.062 & 3033.664 & 0.06985 & 2304.939 \\
\hline $2018 / 1 / 2$ & 0.11773 & 3207.522 & 0.06876 & 2289.276 \\
\hline $2018 / 1 / 3$ & 0.14405 & 3293.061 & 0.07405 & 2286.844 \\
\hline $2018 / 1 / 4$ & 0.1539 & 3325.685 & 0.08124 & 2287.757 \\
\hline $2018 / 1 / 5$ & 0.1536 & 3324.674 & 0.08904 & 2289.846 \\
\hline $2018 / 1 / 6$ & 0.10704 & 3173.431 & 0.09745 & 2292.847 \\
\hline 2018/1/7 & 0.07946 & 3087.091 & 0.10182 & 2289.446 \\
\hline $2018 / 1 / 8$ & 0.14331 & 3290.645 & 0.09513 & 2282.042 \\
\hline $2018 / 1 / 9$ & 0.16458 & 3361.375 & 0.0885 & 2285.797 \\
\hline $2018 / 1 / 10$ & 0.15802 & 3339.389 & 0.07313 & 2290.724 \\
\hline 2018/1/11 & 0.16692 & 3369.262 & 0.06263 & 2298.07 \\
\hline $2018 / 1 / 12$ & 0.16342 & 3357.489 & 0.05746 & 2306.111 \\
\hline $2018 / 1 / 13$ & 0.11318 & 3192.971 & 0.05672 & 2312.369 \\
\hline 2018/1/14 & 0.08018 & 3089.321 & 0.05436 & 2310.86 \\
\hline $2018 / 1 / 15$ & 0.13719 & 3270.569 & 0.05045 & 2302.05 \\
\hline 2018/1/16 & 0.15861 & 3341.388 & 0.05265 & 2305.035 \\
\hline $2018 / 1 / 17$ & 0.16545 & 3364.304 & 0.05551 & 2310.459 \\
\hline 2018/1/18 & 0.18158 & 3418.996 & 0.05946 & 2316.015 \\
\hline $2018 / 1 / 19$ & 0.18215 & 3420.975 & 0.06448 & 2322.07 \\
\hline $2018 / 1 / 20$ & 0.12644 & 3235.607 & 0.06916 & 2329.694 \\
\hline $2018 / 1 / 21$ & 0.09477 & 3134.726 & 0.06967 & 2329.078 \\
\hline $2018 / 1 / 22$ & 0.15018 & 3313.309 & 0.0689 & 2321.845 \\
\hline $2018 / 1 / 23$ & 0.1702 & 3380.337 & 0.07375 & 2326.218 \\
\hline $2018 / 1 / 24$ & 0.17226 & 3387.291 & 0.07978 & 2331.648 \\
\hline $2018 / 1 / 25$ & 0.17926 & 3411.1 & 0.08707 & 2339.563 \\
\hline $2018 / 1 / 26$ & 0.17099 & 3382.984 & 0.09246 & 2346.183 \\
\hline $2018 / 1 / 27$ & 0.12507 & 3231.167 & 0.09703 & 2351.105 \\
\hline $2018 / 1 / 28$ & 0.09899 & 3147.975 & 0.09991 & 2348.306 \\
\hline $2018 / 1 / 29$ & 0.15575 & 3331.844 & 0.10044 & 2339.811 \\
\hline $2018 / 1 / 30$ & 0.18689 & 3437.229 & 0.10369 & 2343.833 \\
\hline $2018 / 1 / 31$ & 0.18483 & 3430.125 & 0.10702 & 2351.569 \\
\hline 2018/2/1 & 0.20174 & 3488.628 & 0.10807 & 2357.44 \\
\hline $2018 / 2 / 2$ & 0.20892 & 3513.788 & 0.10881 & 2365.989 \\
\hline $2018 / 2 / 3$ & 0.16109 & 3349.686 & 0.1119 & 2374.195 \\
\hline $2018 / 2 / 4$ & 0.13594 & 3266.475 & 0.11231 & 2376 \\
\hline 2018/2/5 & 0.21827 & 3546.795 & 0.10882 & 2373.094 \\
\hline $2018 / 2 / 6$ & 0.24062 & 3626.954 & 0.11009 & 2381.991 \\
\hline $2018 / 2 / 7$ & 0.26609 & 3720.525 & 0.11314 & 2392.96 \\
\hline $2018 / 2 / 8$ & 0.25158 & 3666.913 & 0.11634 & 2405.038 \\
\hline $2018 / 2 / 9$ & 0.23556 & 3608.641 & 0.11684 & 2415.651 \\
\hline $2018 / 2 / 10$ & 0.18196 & 3420.321 & 0.11577 & 2424.95 \\
\hline $2018 / 2 / 11$ & 0.1496 & 3311.39 & 0.11117 & 2427.282 \\
\hline Max & 0.062 & 3720.525 & 0.05045 & 2427.282 \\
\hline Min & 0.26609 & 3033.664 & 0.11684 & 2282.042 \\
\hline $\mathrm{CV}$ & $28.12 \%$ & 4.503849 & $24.58 \%$ & 1.723838 \\
\hline
\end{tabular}

E-mail: zhangyueno.8@163.com (Yue Zhang); arash.farnoosh@ifpen.fr (Arash Farnoosh).

Declarations of interest: none. 
E-mail: zhangyueno.8@163.com (Yue Zhang); arash.farnoosh@ifpen.fr (Arash Farnoosh).

Declarations of interest: none. 